\title{
Chain Reduction via Substitution: Evidence from Mayan
}

\section{Glossa}

a journal of general linguistics

\section{GESOEL MENDES [D}

\section{RODRIGO RANERO (1)}

*Author affiliations can be found in the back matter of this article

\footnotetext{
ABSTRACT

We argue that deletion is not the only way that chain links created by $\mathrm{A}^{\prime}$-movement can be affected at PF. Chain links can also be substituted by a morpheme. This substitution delivers a linearizable output (in a manner parallel to deletion), creating overt "traces" on the surface. We demonstrate the virtues of our proposal through the empirical lens of adjunct extraction in two Mayan languages of the K'ichean branch: K'iche' and Kaqchikel. In these languages, extraction of low adjuncts triggers the appearance of a verbal enclitic wi. The distribution of the enclitic upon long distance extraction shows that it must be analyzed as a surface reflex of substitution of a chain link. Our proposal provides evidence that movement proceeds successive cyclically and has two additional theoretical consequences: (i) $C^{0}$ must be a phase head (contra den Dikken 2009; 2017), (ii) $v^{0}$ cannot be a phase head (in line with Keine 2017).
}

\section{CORRESPONDING AUTHOR:}

\section{Rodrigo Ranero}

University of Maryland, 1401 Marie Mount Hall, University of Maryland, College Park, MD rranero@umd.edu

\section{KEYWORDS:}

cyclic movement; Chain Reduction; linearization; phases; Mayan; K'ichean

TO CITE THIS ARTICLE: Mendes, Gesoel and Rodrigo Ranero. 2021. Chain Reduction via Substitution: Evidence from Mayan. Glossa: a journal of general linguistics 6(1): 10. 1-31. DOI: https://doi. org/10.5334/gjgl.1087 


\section{INTRODUCTION}

In minimalism, displacement is usually seen as a by-product of Internal Merge (henceforth IM; Chomsky 2004, et seq.). Adapting ideas from Chomsky (1995), Nunes (2004), and others, we assume that IM results in multiple copies that are dealt with at the interfaces:

a. Robin asked who Leslie saw.

b. (i) Robin asked [ ${ }_{\mathrm{CP}}$ who [IP $_{\mathrm{IP}}$ Leslie saw who]].

(ii) Robin asked [ ${ }_{C P}$ who $\left[{ }_{I P}\right.$ Leslie saw wo] $]$.

Typically, the lower copy is deleted at PF in such configurations. We assume that copy deletion occurs in order to avoid a linearization paradox that would arise from the existence of two instances of the wh-element in two different positions (Nunes 2004). ${ }^{1}$

Here, however, we will argue that displacement is not limited to IM + Deletion at PF. The grammar also allows for copies resulting from IM to be substituted by a morpheme. This IM + Substitution procedure creates overt "traces" of movement that cannot be assimilated into any independent lexical category of a language. We will call the mechanism that creates these overt traces Chain Reduction via Substitution.

The empirical domain we will use to argue for our position is $A^{\prime}$-extraction of low adjuncts in two closely-related Mayan languages of the K'ichean branch: K'iche' and Kaqchikel. It has been observed that low adjunct extraction in these languages, and across the K'ichean branch of the family, triggers the appearance of a verbal enclitic wi (Dayley 1985 for Tz'utujil; Silberman 1995; Henderson 2008; González 2016 for Kaqchikel; England 1997; Velleman 2014; Can Pixabaj 2015 for K'iche'; see section 6). In the Mayanist literature, this enclitic is usually called a fronting particle (Spanish: partícula de adelantamiento) (e.g., García Matzar \& Rodríguez Guaján 1997 for Kaqchikel). ${ }^{2}$ We will use this terminology moving forward. We will observe here that the fronting particle is obligatory in K'iche' and optional in Patzún Kaqchikel, the dialect of Kaqchikel that we describe here in depth. ${ }^{3}$

(2) The fronting particle in K'iche' (Adapted from Velleman 2014: 41-42)

Jawi $\mathrm{x}$-at-b'ee *(wi) iwiir?

where $\mathrm{COM}-\mathrm{B} 2 \mathrm{~s}-\mathrm{go}$ *(FP) yesterday

'Where did you go yesterday?'

(3)

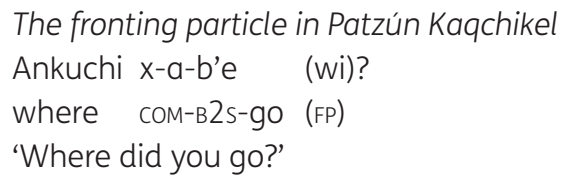

We will argue that the fronting particle is an overt trace, here understood in terms of Chain reduction via Substitution. ${ }^{4}$ We formulate Chain reduction in K'iche' and Kaqchikel as follows:

(4)

Chain Reduction

Given a nontrivial chain $\mathrm{CH}=\left\langle\mathrm{XP}_{1}, \mathrm{XP}_{2}, \ldots\right\rangle$

a. Substitute

$\mathrm{XP}_{[\text {[AppL(ICATIVE)] }} \rightarrow=$ wi

(substitute XP bearing [APPL] feature by / = wi/)

b. Delete

$\mathrm{XP} \rightarrow \varnothing$ (elsewhere)

(delete XP)

c. General conditions on (a) and (b): Recoverability of deletion and economy (Nunes 2004)

1 We will not discuss here how multiple copies are treated in the interpretive component. See Chomsky (1993), Fox (2002) i.a.

2 While the fronting particle is spelled $\langle$ wi $\rangle$, the pronunciation of the vowel varies between being lax and tense in Kaqchikel, with speakers reducing it to schwa in fast speech. See Patal Majzul et al. 2000: 171 for a description of allophones of /w/ across Kaqchikel dialects.

3 The data come either from the literature or our own fieldwork in Guatemala (2016-2018).

4 The idea that wi should be analyzed as a trace is already suggested in López Ixcoy 1997, Garciá Matzar \& Rodríguez Guaján 1997 and Can Pixabaj 2015. 
(4b) instantiates Nunes (2004)'s Chain Reduction. ${ }^{5}$ The novelty of our proposal comes from (4a), which allows chain links to undergo substitution, rather than deletion. The substitution here applies to low adjuncts, which we assume attach at the Appl(licative)P layer between VP and VP (Pylkkänen 2002; 2008). Via this assumption, we can delimit the types of phrases that trigger the fronting particle. We will return to the details of the structural position of the relevant adjuncts in section 2 .

We will also argue for two other theoretical claims. First, $\mathrm{C}^{0}$ must be a phase head (contra den Dikken 2009; 2017). Second, $v^{0}$ is not a phase head (contra Chomsky 2001 i.a.; see Keine 2017). ${ }^{6}$ The empirical generalization that supports these claims was first discussed by Can Pixabaj (2015) and is the following:

(5) Fronting particle generalization: In long distance $A^{\prime}$-extraction of low adjuncts from a single embedded clause, the presence of wi in the matrix clause is contingent on the presence of an overt complementizer in the embedded clause.

The claim that the fronting particle is an overt trace, alongside our defense that $\mathrm{C}^{0}$ is the only phase head, straightforwardly explains the otherwise puzzling distribution of the fronting particle in long-distance extraction.

This paper is divided into seven sections. Section 2 describes the phenomenon. Section 3 develops our analysis. Section 4 argues against four competing analyses, showing that none of them is tenable. Specifically, we show that the fronting particle is not (i) an applicative head, (ii) a resumptive pronoun, (iii) a movement trigger or an instance of wh-agreement, or (iv) an element akin to the Agent Focus morpheme. Section 5 discusses the theoretical consequences of our analysis. Section 6 outlines avenues for future research. Section 7 concludes.

\section{EMPIRICAL FACTS}

K'iche' and Kaqchikel are closely related K'ichean Mayan languages that share several grammatical features, summarized below:

Morphosyntax of K'iche' and Kaqchikel

a. Word order: Basic word order is VOS (García Matzar \& Rodríguez Guaján 1997 for Kaqchikel; López Ixcoy 1997; Can Pixabaj 2015; 2017 for K’iche'; England 1991; Clemens \& Coon 2018 for word order across Mayan). Preverbal subjects are also common in discourse in both languages (see Can Pixabaj \& England 2011 for discussion of SVO in K'iche').

b. Morphological ergativity: Transitive subjects control ergative agreement on the verb, while transitive objects and the sole argument of intransitive predicates control absolutive agreement (García Matzar \& Rodríguez Guaján 1997; López Ixcoy 1997). ${ }^{8}$

c. Syntactic ergativity: The external argument of a transitive clause cannot be $\mathrm{A}^{\prime}$-extracted in the active voice. Instead, the Agent Focus or oblique antipassive voices are required (see Larsen \& Norman 1979; Davies \& Sam-Colop 1990; Aissen 2011; Coon et al. 2014; Assmann et al. 2015; Erlewine 2016; Polinsky 2016; Aissen 2017b; Douglas et al. 2017; Ranero 2020). 
d. Aspect: Verbs inflect for aspect, not tense, and finiteness is aspect-driven (García Matzar \& Rodríguez Guaján 1997; López Ixcoy 1997).

e. Pro-drop: Pro-drop of subject and object (García Matzar \& Rodríguez Guaján 1997; López Ixcoy 1997).

f. Relational nouns: a Mayan-specific lexical class similar to adpositions in other languages; e.g., they describe spatial relations. They also introduce oblique arguments in passives and antipassives (García Matzar \& Rodríguez Guaján 1997; López Ixcoy 1997).

For the sake of simplicity, we will assume the following basic clause structure for VOS word order in both languages, based on Aissen 1992: ${ }^{2}$

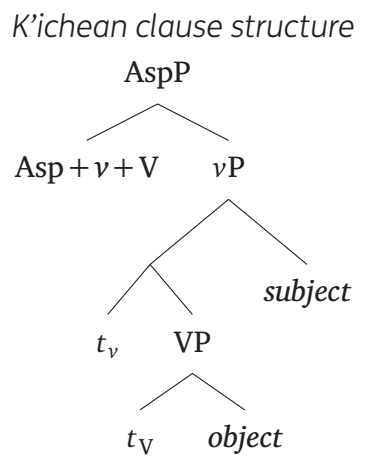

A second assumption we will make is that the relevant adjuncts we discuss are introduced at the level of ApplP (Pylkkänen 2002; 2008) merged above VP (Pylkkänen's high applicative). ${ }^{10}$

(8)

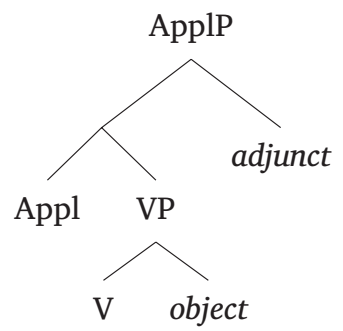

We are aware that the adjunct versus argument distinction is blurred by assuming that the phrases that trigger wi are introduced by an applicative. We will not add to the complex discussion regarding how to capture the asymmetry between arguments and adjuncts in general. Instead, our assumption about the position of the relevant adjuncts in the clause, as will become clear in the next section, allows us to group them as a natural class, which is necessary for any account of the phenomenon. There might be alternatives that are preferable upon closer scrutiny, but the proposal in (8) allows us to discuss the phenomenon without deviating into issues that are tangential to our main contribution. We therefore will assume (8), leaving possible refinements for the future. ${ }^{11}$

With these assumptions in place, let us turn to our empirical focus. In Kaqchikel and K'iche', $\mathrm{A}^{\prime}$-extraction (wh-movement, focus, relativization) of a class of low adjuncts (locatives, instrumentals, comitatives, indirect objects ${ }^{12}$, etc.) triggers a verbal enclitic wi. For reasons of space, we present just two examples below from each language, focusing on wh-

9 We are aware that VOS order could be derived via object shift above the subject (Douglas et al. 2017) or post-syntactically (Clemens \& Coon 2018). Since the derivation of basic word order is not crucial here, we will follow (Aissen 1992). We use AspP here, but others use TP/IP. For ease of presentation, we also abstract away from a more articulated verbal domain including a VoiceP layer or additional layers.

10 We assume that $\mathrm{Appl}^{0}$ is null.

11 Henderson 2008 assumes a similar analysis: "the adjunct counterparts of the high applicatives form the class of adjuncts that trigger wi under preposing."

12 By indirect objects we mean oblique arguments introduced by relational nouns in prototypical ditransitive frames. 
movement. The fronting particle is obligatory in K'iche', but optional in the Patzún dialect of Kaqchikel: ${ }^{13}$

(9) K'iche': wi is obligatory

a. Jawi x-at-b'ee *(wi) iwiir?

where $\left.\mathrm{COM}-\mathrm{B} 2 \mathrm{~s}-\mathrm{go}{ }^{*} \mathrm{FP}\right)$ yesterday

'Where did you go yesterday?'

(Adapted from Velleman 2014: 41-42)

b. Jas r-uuk' $x$ - $\varnothing$-ki-tij wile ki-rikiil?

WH A3s-RN COM-B3s-A3P-eat FP DET A3P-food

'With what did they eat their food?' (Adapted from Can Pixabaj 2015: 162)

(10)

Patzún Kaqchikel: wi is optional

a. Ankuchi $x-\varnothing$-tzopin (wi) a Lu’?

where cOM-B3s-jump (FP) CLF Pedro

'Where did Pedro jump?'

b. Achoj k'in $x-\varnothing$-u-qupij (wi) ru-wäch che' ri Ixchel?

WH RN COM-B3s-A3s-cut (FP) A3s-eye tree DET Ixchel

'What did Ixchel cut fruits with?'

The fronting particle is generally unavailable with an in-situ adjunct in either language (regardless of information structure, see 4.2): ${ }^{14}$

Patzún Kaqchikel: no wi with in-situ adjunct

Ri a Lu' $\quad x$ - $\varnothing$-tzopin (*wi) chwa jay.

DET CLF Pedro COM-B3s-jump ( ${ }^{*}$ FP) PREP.A3S.RN house

'Pedro jumped in the garden.'

Only low adjuncts trigger wi. Clausal adjuncts such as reason and temporal adverbs do not.

(12) Temporal adjunct extraction in Kaqchikel
a. $\quad \mathrm{N}-\varnothing$-a-bän ri qa-way pa toq'a.
INC-B3S-A2s-make DET A1P-food PREP night
'You make our food at night.'

b. *Pa toq'a $n-\varnothing$-a-bän wi ri qa-way. PREP night INC-B3s-A2s-make FP DET A1P-food 'At night you make our food.'

(Adapted from Henderson 2008)

C. A: Jampe' $x$ - $\varnothing$-a-tej knaq’?

when COM-B3s-A2s-eat beans

'When did you eat beans?'

B: [Iwir $]_{F} \quad x$ - $\varnothing$-in-tej ( ${ }^{*}$ wi) knaq'. yesterday сOM-B3s-A1s-eat ( $\left.{ }^{*} \mathrm{FP}\right)$ beans 'I ate beans [yesterday].'.

(13) Temporal adjunct extraction in K'iche' (Adapted from Velleman 2014: 194)

a. Context: When did the mice eat the clothes?

b. [Chaq'ab'] $]_{F}-\varnothing-k i-k$ 'ux le atz'yaq. PREP.night COM-B3s-A3P-eat DET clothes 'They ate the clothes [last night].'

13 The mere appearance of the adjunct in the left-periphery does not trigger wi. If an adjunct serves as a topic, the particle is not triggered (Can Pixabaj 2009):

(i) K'iche': no wi with topicalized adjunct (Adapted from Can Pixabaj 2009: 1)

Waraal, k- $\varnothing$-in-ya' ju-paaj ka-paaj un-tziij.

here INC-B3s-A1s-give one-MEAs tWo-MEAS A1s-word

'Here, I will say a few words.'

See England 2009, Can Pixabaj \& England 2011 and Can Pixabaj 2017 for discussion of information structure and the left-periphery in K'iche', and Velleman 2014 and Yasavul 2017 for focus specifically. The same holds for Kaqchikel, although investigating the left-periphery in-depth is pending.

14 See section 6 for discussion of other uses of wi. 
What we observe, then, is that a class of adjuncts triggers the appearance of the fronting particle, whereas another class of adjuncts does not.

An important issue is whether $A^{\prime}$-processes involving low adjuncts are the result of syntactic movement. In parallel fashion to A'-extraction of arguments, both K'iche' and Kaqchikel lowadjunct extraction is subject to island effects. We take this to mean that movement is implicated. ${ }^{15}$

(15) Island effects in K'iche' low-adjunct A'-extraction (Adapted from Can Pixabaj 2015: 224 and T. Can Pixabaj p.c.)

a. K-in-chakun-ik r-eech k-at-wa' pa tijob'al. INC-B1s-work-sS A3s-RN INC-B2s-eat PREP school

'I work so that you can eat at school (because I pay for it).'

b. *Jawi k-at-chakun-ik (wi) r-eech k-at-wa' (wi).

where INC-B2s-work-SS (FP) A3s-RN INC-B2s-eat (FP)

Intended: 'What is the place such that you work so that you can eat in that place?'

Island effects in Kaqchikel adjunct $A^{\prime}$-extraction

a. *Ankuchi $x-\varnothing$-a-tz'ët ri achin ri $x-\varnothing$-tj-o wi jun aq?

where COM-B3S-A2S-See DET man REL COM-B3S-eat-AF FP a pig

Intended: 'Which is the place such that you saw the man that ate a pig at such a place?'

b. *Ankuchi $x-\varnothing$-a-tz'ët wi ri achin ri $x-\varnothing$-tj-o wi jun aq?

where COM-B3S-A2S-See FP DET man REL COM-B3S-eat-AF FP a pig

Intended: 'Which is the place such that you saw the man that ate a pig at such a place?'

Having established that movement is implicated when adjuncts are $\mathrm{A}^{\prime}$-extracted, let us turn to the behavior of the fronting particle upon long-distance extraction. The peculiarities and relevance of the fronting particle's distribution in this context were first established by Can Pixabaj (2015), so our work is an extension of her observations. ${ }^{16}$ Consider first the examples below, where an overt complementizer introduces the embedded clause. In K'iche', the fronting particle must appear both in the matrix and embedded clause.

K'iche' extraction from embedded CP: multiple wi (Adapted from Can Pixabaj 2015: 166-167)

Jawi $x-\varnothing-k i-b^{\prime} i j \quad *$ *(wi) chi k-e-'e $\quad *($ wi $)$ ?

where COM-B3s-A3s-Say *(FP) COMP INC-B3P-go *(FP)

'Where did they say that they would go?'

In a parallel Kaqchikel example, the appearance of the particle in each of the two clauses is optional. In other words, there are four acceptable versions of the following example: (i) wi in both clauses, (ii) no wi, (iii) wi only in the embedded clause, and (iv) wi only in the matrix clause.

$$
\begin{aligned}
& \text { Kaqchikel extraction from embedded CP: multiple wi } \\
& \text { Ankuchi } x-\varnothing-u-b \text { 'ij } \quad \text { (wi) Maria chi } x-\varnothing-u-t e j \quad \text { (wi) knaq' Juan? } \\
& \text { where соM-B3s-A3s-say (FP) Maria сомp сом-B3s-A3s-eat (FP) beans Juan } \\
& \text { 'Where did Maria say that Juan ate the beans?' }
\end{aligned}
$$

Let us move on now to long-distance extraction from reduced clauses, which we will call AspPs. The verbs in the examples shown below select for clauses that are not introduced by an overt complementizer. In this example type, the fronting particle appears only in the embedded clause. Here, once again, the particle is obligatory in K'iche' and optional in Kaqchikel:

15 Henderson 2008 provides evidence from crossover effects as well. 
K'iche' extraction from embedded AspP: wi in embedded clause (Adapted from Can Pixabaj 2015: 163 and T. Can Pixabaj p.c.)
Jas r-uuk' k- Ø-a-rayii-j
( ${ }^{*}$ wi) $\mathrm{k}-\varnothing-\mathrm{a}-\mathrm{tij}$
*(wi) le wa?

WH A3s-RN INC-B3s-A2s-desire-ACT ( ${ }^{*} F$ P) INC-B3s-A2s-eat *(FP) DET food

'With what do you desire to eat the food?'

(20)

Kaqchikel extraction from embedded AspP: wi in embedded clause
a. Ankuchi $x-\varnothing$-u-rayij
(*wi) $\mathrm{x}-\varnothing$-u-tz'ët
(wi) xta Ixchel?
where сOM-B3s-A3s-desire ( $\left.{ }^{*} \mathrm{FP}\right)$ СOM-B3S-A3S-see (FP) CLF Ixchel
'Where did s/he desire to see Ixchel?'
b. Achoj k'in $x$ - $\varnothing$-a-tojtob'ej ( ${ }^{*}$ wi) $x$ - $\varnothing$-a-löq' (wi) ri kotz'i'j? WH RN COM-B3S-A2s-try ( $\left.{ }^{*} F \mathrm{P}\right)$ COM-B3S-A2s-buy (FP) DET flowers 'Who did you try buying the flowers with?'

The empirical generalization so far is given below:

(21) Fronting particle generalization: In long distance $A^{\prime}$-extraction of low adjuncts from a single embedded clause, the presence of wi in the matrix clause is contingent on the presence of an overt complementizer in the embedded clause.

(repeated from (5))

This generalization will be the main driving force of our analytical claims in what follows.

Before we proceed, it is important to understand the structural differences between the two types of embedded clauses that we contrasted (CPs vs. AspPs; see Aissen 2017a for discussion across Mayan). Setting aside the distribution of the fronting particle, independent diagnostics show that embedded clauses without an overt complementizer are structurally smaller than embedded clauses with an overt complementizer. Several tests supporting this claim have been documented for both languages in the literature (Ajsivinac Sian 2007 and Can Pixabaj 2015 for discussion on Kaqchikel and K'iche' respectively). Let us illustrate the asymmetry first via the following diagnostic: The clauses that we have deemed AspPs cannot host sentential negation, showing that they are reduced in comparison to $\mathrm{CPs}:{ }^{17}$

K'iche': CP complements can host sentence negation, AspP complements cannot INC-B3s-A1p-see-sS [COMP NEG INC-B1P-A3s-receive IRR ]

'We realize that $s /$ he would not receive us.'

(Can Pixabaj 2015: 90)

b. *X-Ø-in-xi'j W-iib' [na $x$-in-ch'aaw taj ]. COM-B3s-A1s-be.afraid A1s-REF [NEG COM-B1s-talk IRR ] Intended: 'I was afraid to not talk.'

(Can Pixabaj 2015: 98)

(23)

Kaqchikel: CP complements can host sentence negation, AspP complements cannot
a. $\quad \mathrm{X}-\varnothing$-u-b'ij
a Xwan chi man $x$ - $\varnothing$-u-tz'ët
ta jun kuk.
COM-B3S-A3s-say CLF Juan COMP NEG COM-B3S-A3s-see NEG a squirrel 'Juan said that he didn't see a squirrel.'

(Adapted from Ajsivinac Sian 2007)
b. *Ri ma Lu' $\quad x-\varnothing$-u-rayij man $x-\varnothing$-u-tz'ët ta xta Ixchel. DET CLF Pedro COM-B3s-A3s-desire NEG COM-B3s-A3s-see NEG CLF Ixchel Intended: 'Pedro desired to not see Ixchel.'

Five other diagnostics are the following: (i) AspPs cannot host topics in the left periphery, but CPs can (Ajsivinac Sian 2007; Can Pixabaj 2015), (ii) CPs can be extraposed, but AspPs cannot be (Ajsivinac Sian 2007), ${ }^{18}$ (iii) AspPs cannot host focused phrases in the left-periphery, but CPs

17 Can Pixabaj 2015 notes that there is some variation of size within the complement clauses we have called AspPs. Some are able to host negation, even though they pattern identically to other AspPs regarding the long-distance extraction data. What is crucial for our purposes is that there is a class of reduced clauses which lacks the CP layer

18 This asymmetry seems to hold only in Kaqchikel. AspPs can be extraposed in some dialects of K'iche' (López Ixcoy 1997) and in the dialect reported in Can Pixabaj 2015, they must be extraposed. 
can (Can Pixabaj 2017), (iv) there is more freedom regarding the choice of TAM in a CP than an AspP-in an AspP, the choice of TAM is limited by the TAM of the matrix clause (although strict matching is not necessary for all cases) (Can Pixabaj 2015; 2017), and (v) the subject of an AspP complement must be controlled by an argument of the matrix clause (subject or object control), whereas such a restriction does not obtain with CP complements (Ajsivinac Sian 2007; Can Pixabaj 2017).

We will not show all of the above diagnostics for reasons of space, but illustrate the asymmetry between CP and AspP further via the Kaqchikel examples below (for K'iche' see Can Pixabaj 2015: 90, 98). Whereas embedded CPs allow for topic and focus in their left-periphery, embedded AspPs do not (see Larsen 1988: 392 for related observations in K'iche'): ${ }^{19}$

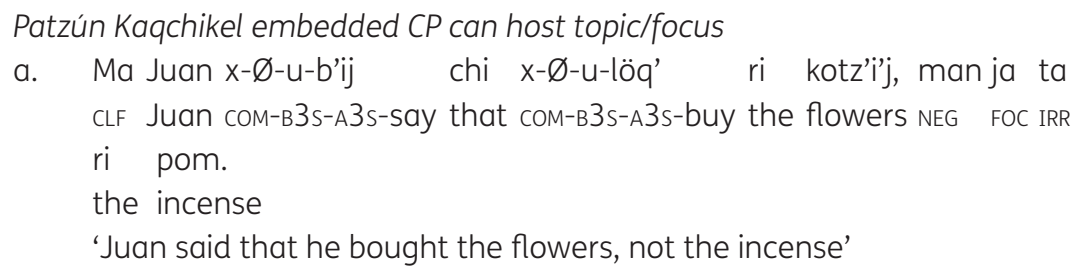

b. Ma Juan $x-\varnothing-u-b$ 'ij chi ri kotz'i'j $x-\varnothing-u-l o ̈ q ', \quad$ man ja ta CLF Juan сOM-B3s-A3s-say that the flowers COM-B3s-A3s-buy NEG FOC IRR ri pom.

(25) Patzún Kaqchikel embedded AspP cannot host topic/focus
a. $\quad X$ - $\varnothing$-in-tojtob'ej $x$ - $\varnothing$-in-kam-sa-j ri amolo'. COM-B3s-A1s-try cOM-B3s-A1s-die-CAUS-ACT DET fly 'I tried to kill the fly'
b. ${ }^{*} X-\varnothing$-in-tojtob'ej ri amolo' $x-\varnothing$-in-kam-sa-j. COM-B3s-A1s-try DET fly COM-B3s-A1s-die-CAUS-ACT Intended: 'I tried to kill the fly'
c. ‘X- $\varnothing$-in-tojtob'ej ja ri amolo’ $x$ - $\varnothing$-in-kam-sa-j. COM-B3s-A1s-try FOC DET fly COM-B3s-A1s-die-CAUS-ACT Intended: 'I tried to kill THE FLY.'

It is crucial to note that, even though the embedded clause in the AspP examples is reduced and the verbal morphology on the embedded verb is parasitic on the matrix clause (see Can Pixabaj 2015), the matrix verb projects its own clausal structure and does not belong to the extended projection of the embedded verb, as proposed in some analyses of restructuring constructions (see Cinque 2006; Grano 2017 i.a.). In cases where the matrix verb can be incorporated into the extended projection of the embedded verb (as in Romance and German) the embedded verb typically receives infinitival morphology (see Wurmbrand 1998). The presence of inflectional morphology in both verbs in K'ichean indicates that they do not belong to the same clausal structure. Following Can Pixabaj (2015), we take the reduced clausal structure of the embedded clause in AspP examples to be governed by selectional properties of the matrix verb.

Moving forward, then, we will take embedded clauses with an overt complementizer to be CPS and embedded clauses without a complementizer to be AspPs.

To summarize, we have established the behavior of the fronting particle in K'iche' and Patzún Kaqchikel. Most importantly, we discussed how the distribution of the fronting particle varies in long-distance extraction, depending on the size of the complement clause from which the 
extraction takes place. This latter observation will be crucial for assessing the consequences of our analysis, a matter we now turn to.

\section{CHAIN REDUCTION VIA DELETION OR SUBSTITUTION}

As stated in the introduction, we assume that internal merge (IM) results in multiple copies. $^{20}$

a. Robin asked who Leslie saw.

b. (i) Robin asked [ ${ }_{C P}$ who [ ${ }_{\text {IP }}$ Leslie saw who]].

(ii) Robin asked $\left[_{C P}\right.$ who $\left[_{I P}\right.$ Leslie saw who $]$. PF: Chain Reduction

For the sake of simplicity, we assume that phrase markers encode linear order. ${ }^{21}$ To the extent that copies resulting from IM count as identical, IM in examples like (26) would create a linearization paradox at PF. Without affecting either copy, PF would need to output an order where who both follows and precedes Leslie saw. The paradox in examples like the above is typically avoided by deleting the lower copy.

We attribute the appearance of the fronting particle in K'ichean to the application of Chain Reduction, a PF operation (Nunes 2004). We propose that there are two possible ways of applying Chain Reduction in K'iche' and Kaqchikel: (i) the unmarked case, via deletion and (ii) the more specific case, via substitution. In the latter case, the relevant copy of the moved wh-phrase is replaced by wi. This operation performs the same function that deletion does (circumventing an ordering paradox).

Let us now illustrate the analysis step-by-step. First, low adjuncts must be distinguished from other constituents in the clause, which could be implemented in different ways. For concreteness, we assume that the Appl head transmits an [APPL(ICATIVE)] feature to the adjunct via Spec-head agreement (Chomsky 1993; Koopman 2006 among many others). ${ }^{22}$

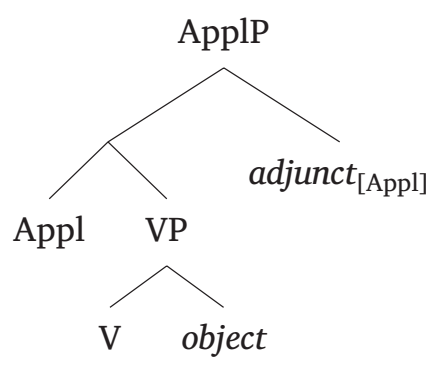

Recall a simple monoclausal example with adjunct extraction:

$$
\begin{aligned}
& \text { K'iche' monotransitive adjunct extraction (Adapted from Can Pixabaj 2009) } \\
& \text { Jas r-uuk' x- } \varnothing \text {-ki-tij wi le ki-rikiil? } \\
& \text { WH A3S-RN COM-B3s-A3P-eat FP DET A3P-food } \\
& \text { 'With what did they eat their food?' }
\end{aligned}
$$

An example like this would have the following underlying structure prior to Chain Reduction:

20 The copy theory of movement receives support from cases where lower copies are activated either on the LF side (reconstruction effects; see Chomsky 1995 i.a.) or on the PF side (multiple copy pronunciation; see Nunes 2004; Bošković \& Nunes 2007; Kandybowicz 2008; Bastos-Gee 2009). These phenomena are difficult to capture under trace theory. We will not discuss what the best way is to implement the preference for lower copy deletion on the PF side (see footnote 5).

21 We depart from Nunes (2004) and do not adopt the LCA as the linearization algorithm, though the main point of our proposal is consistent with it. Adopting the idea that phrase markers encode linear order simplifies drastically the presentation of the material and reinforces the claim that our analysis is not contingent on any particular linearization algorithm. The key insight is that copies must be affected at the PF interface in order to avoid a linearization paradox, regardless of one's adoption of a specific linearization algorithm.

22 The same result could in principle be achieved via feature percolation (see Norris 2014 for a recent formulation of this mechanism). 
(29)

$$
\text { Adjunct IM }
$$

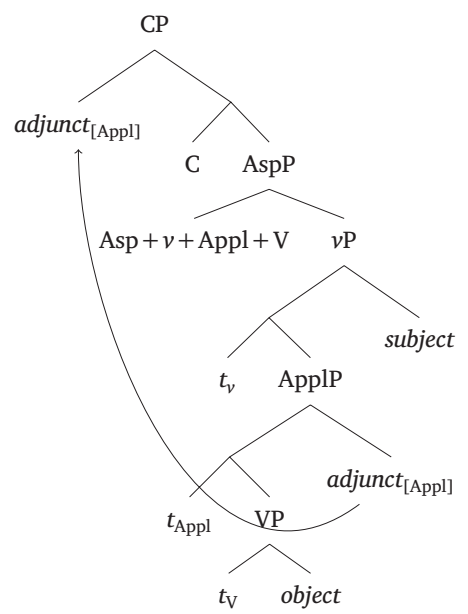

IM delivers a copy of the adjunct in Spec,CP. As a result, the adjunct is required to both follow and precede the verbal complex, creating a linearization paradox. We assume that Chain Reduction in K'iche' and Kaqchikel applies to avoid the paradox and has the following format (note that we assume that the fronting particle is a clitic that attaches upwards to the verb stem):23

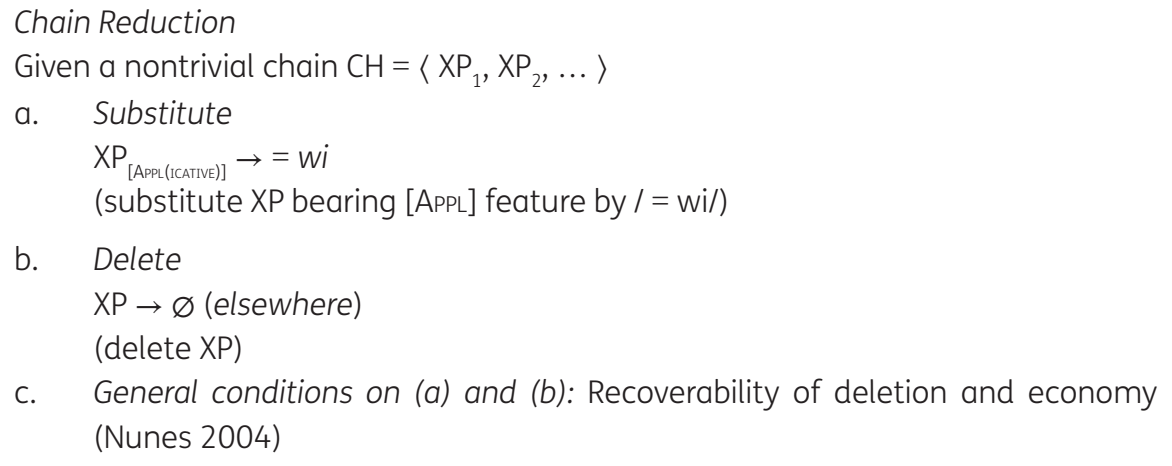

In K'iche', where the fronting particle is obligatory, the choice between Chain Reduction via Deletion and Chain Reduction via Substitution is controlled by the Elsewhere Condition (Kiparsky 1973). Thus, when the links of the chain have an [APPL] feature, substitution applies. When the fronted element does not bear [APPL], deletion (the Elsewhere procedure) applies. In the monotransitive example above, then, the lower copy of the adjunct is substituted by $=$ wi, which cliticizes to the verb complex in the morphophonological component. ${ }^{24}$

K'iche': Chain Reduction via Substitution and subsequent cliticization

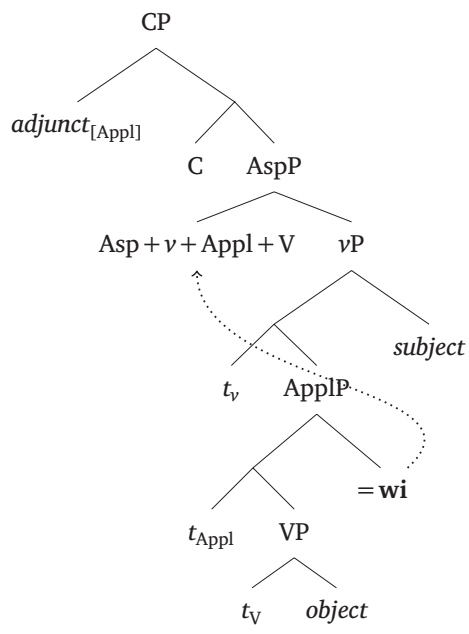

23 An economy condition prevents scattered deletion when the moved element is complex (but see Bošković \& Nunes 2007).

24 It is possible that cliticization on the verb happens before verb movement if verb movement actually occurs at PF (Chomsky 2000; but see Roberts 2010 i.a.). We set aside the question of the ordering of other enclitics on the verbal stem in relation to wi; see Henderson 2008 for some discussion. 
Recall that in Patzún Kaqchikel, the fronting particle is optional. We propose that speakers learn from positive evidence that the Substitution rule that applies to XP[ApPL] is optional, given that the primary linguistic data contains examples with and without the fronting particle. We assume, then, that this is enough for speakers to conclude that the Substitution rule need not apply. If the Substitution rule is not applied, then an XP[APPL] undergoes Deletion.

$$
\begin{aligned}
& \text { Kaqchikel monotransitive adjunct extraction } \\
& \begin{array}{ll}
\text { Achoj k'in } x-\varnothing \text {-u-qupij } \quad \text { (wi) ru-wäch che' ri Ixchel? }
\end{array}
\end{aligned}
$$$$
\text { WH RN COM-B3s-A3s-cut (FP) A3s-eye tree DET Ixchel }
$$

'What did Ixchel cut fruits with?'

\section{Kaqchikel: Chain Reduction via Substitution or Deletion}

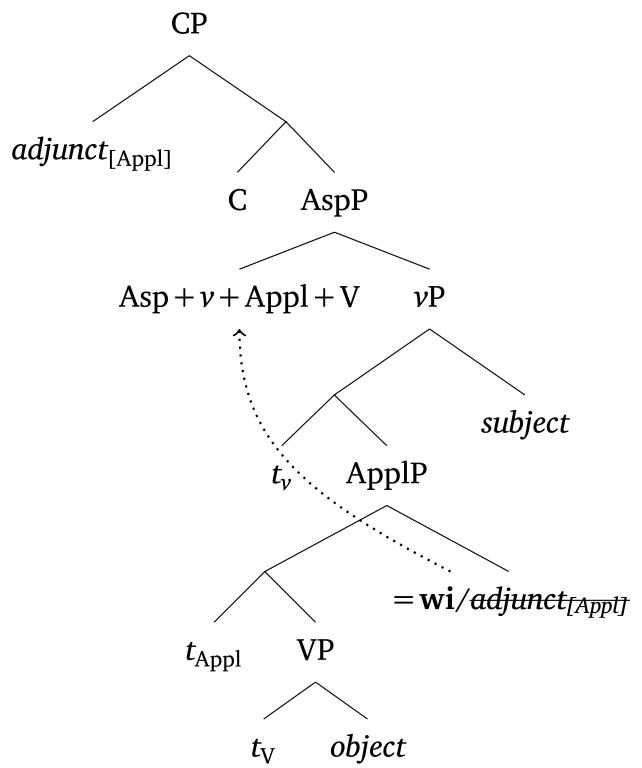

In sum, Chain Reduction via Deletion is operative in both languages. K'iche' and Kaqchikel differ only in the obligatoriness of the substitution rule that would preempt the elsewhere deletion rule.

Let us move on now to the more complex cases of long-distance extraction. We showed that the presence of the fronting particle in the matrix clause is contingent on the presence of an overt complementizer in the embedded clause:

(34) K'iche' extraction from embedded CP: multiple wi (Adapted from Can Pixabaj 2015: 166-167)

Jawi $\quad x-\varnothing-k i-b ' i i j \quad *($ wi $)$ chi k-e-'e $\quad *($ wi $)$ ?

where COM-B3S-A3P-Say *(FP) COMP INC-B3P-gO *(FP)

'Where did they say that they would go?'

(35) K'iche' extraction from AspP: wi in the embedded clause (Adapted from Can Pixabaj 2015: 163 and T. Can Pixabaj p.c.)
Jas r-uuk' k- $\varnothing$-a-rayii-j
$\left({ }^{*}\right.$ wi) $k-\varnothing-a-t i j$
*(wi) le wa?
WH A3s-RN INC-B3S-A2s-desire-ACT ( $\left.{ }^{*} F P\right)$ INC-B3S-A2s-eat *(FP) DET food
'With what do you desire to eat the food?'

We do not repeat the Kaqchikel data, which differ only in the optionality of the fronting particle (see (18) and (20)).

The empirical generalization stemming from the data above is given in (21). We also saw evidence that embedded clauses that are not introduced by an overt complementizer are structurally reduced, instantiating AspP.

With all of this in mind, let us illustrate the analysis. We assume that $C^{0}$ is a phase head. As a result, Spec, $\mathrm{CP}$ is an obligatory stopover point in a movement dependency. In long-distance extraction from a full CP, then, movement of the adjunct from its base position to Spec,CP of the matrix clause proceeds in successive-cyclic fashion through an intermediate step in the embedded Spec,CP headed by the overt complementizer. Assume for now that VP is not a phase, an issue we will expand on in the discussion section. 
We can now see why the presence of the fronting particle in the matrix clause is contingent on the presence of an overt complementizer in the embedded clause: the adjunct has to stop in the embedded Spec,CP. This intermediate copy undergoes Chain Reduction via Substitution by wi, which then attaches upward to the nearest verb-like element.

$$
\text { Chain Reduction via Substitution: extraction from CP }
$$

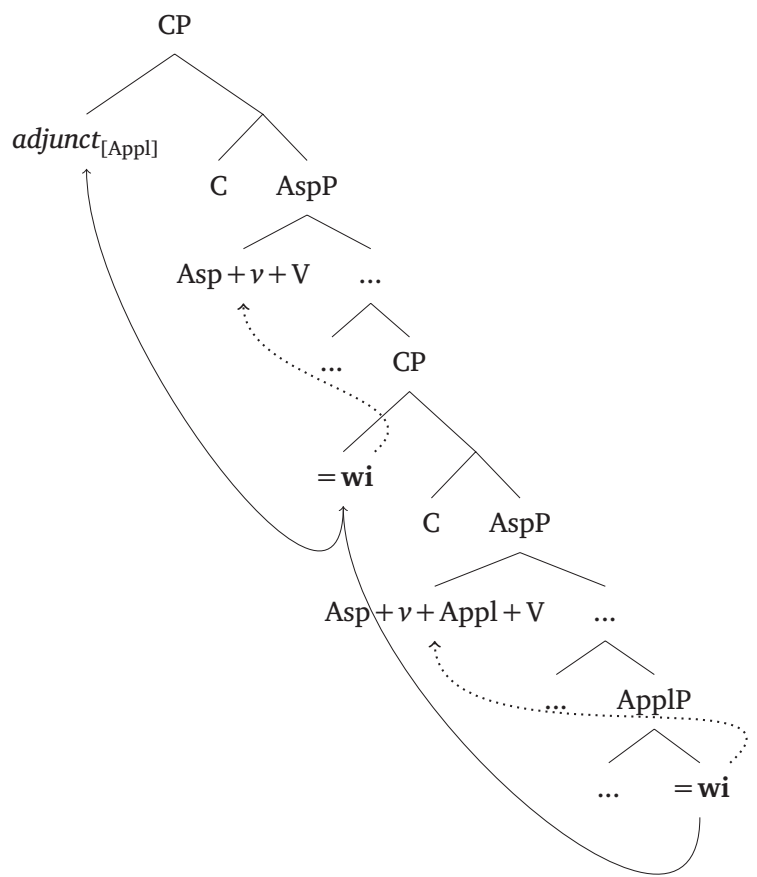

In order to derive the pattern with extraction from AspPs, we follow the analysis first suggested by Can Pixabaj (2015: 168) - if the embedded clause lacks an overt complementizer (thus lacking a (P), movement of the adjunct occurs in one fell swoop.

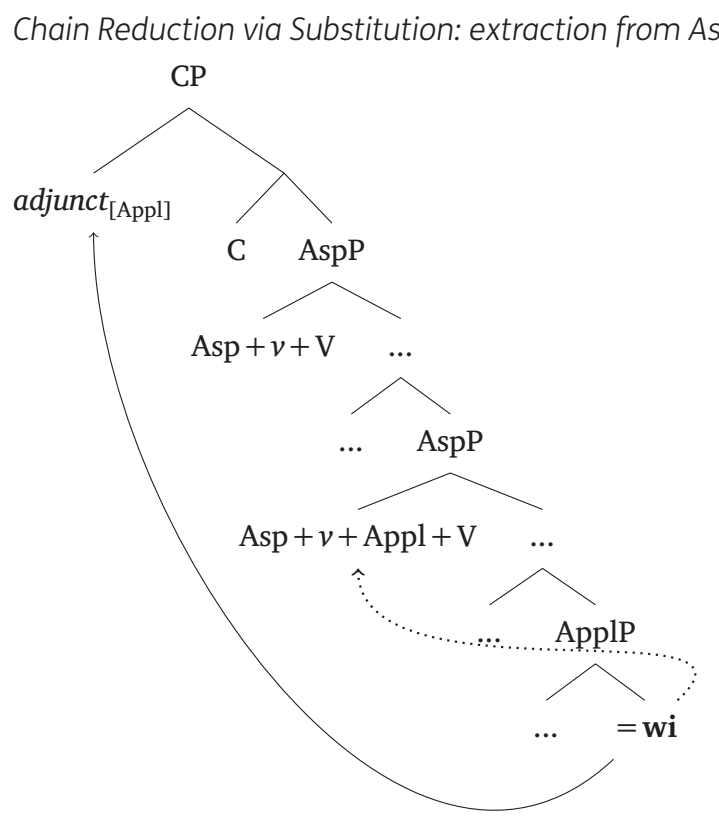

We have now derived the behavior of wi in long-distance extraction.

We note that the examples with extraction from CP (where multiple fronting particles appear), show that one could not derive the connection between the fronting particle and (low) adjuncts exclusively from the base position of the adjunct, since any structural asymmetry between the relevant adjuncts and arguments is neutralized in the stopover in Spec,CP. Nevertheless, a wi stemming from the intermediate Spec, CP copy appears in the matrix clause. Put differently, it is necessary for the relevant adjuncts to carry a feature that is present in every chain link.

Let us summarize our analysis. The fronting particle in K'ichean is the result of applying Chain Reduction via Substitution to links in $\mathrm{A}^{\prime}$-movement chains bearing [APPL]. The distribution of wi in long-distance dependencies is explained via the requirement of a stopover in Spec,CP, as well 
as the lack of a corresponding stopover in Spec,VP. If extraction proceeds from a clause lacking a CP layer, no such intermediate step occurs. ${ }^{25}$

\section{ALTERNATIVE ANALYSES}

In this section, we assess four competing analyses of the phenomenon:
Alternative analyses (to be rejected)
a. The fronting particle is the spell-out of an applicative head.
b. The fronting particle is a (resumptive) pronoun.
c. The fronting particle is the spell-out of the movement triggering head (wh-agreement).
d. The fronting particle is parallel to the Agent Focus morpheme.

We will argue that none of these analyses are tenable.

\subsection{THE FRONTING PARTICLE IS NOT AN APPLICATIVE HEAD}

González (2016) suggests that the fronting particle is itself an applicative. ${ }^{26}$

In order to assess this analysis, let us be wholly explicit. Assume that the fronting particle is the spell-out of the applicative head (Baker 1988; Pylkkänen 2008) that introduces the adjunct. Data below from Chichewa illustrate the flavor of the analysis. The morpheme -ir is the spellout of the head introducing an instrumental.

Chichewa applicative (Adapted from Baker 1988: 300)
a. Mavuto a-na-umba-a mtsuko.
Mavuto SA-PST-mold-ASP waterpot
'Mavuto molded the waterpot.'
b. Mavuto a-na-umb-ir-a mpeni mtsuko.
Mavuto SA-PST-mold-APPL-ASP knife waterpot
'Mavuto molded the waterpot with a knife.'

Applied to K'ichean, wi would be parallel to the overt applicative morpheme above. We would assume, then, that wi instantiates the applicative head.

(40)

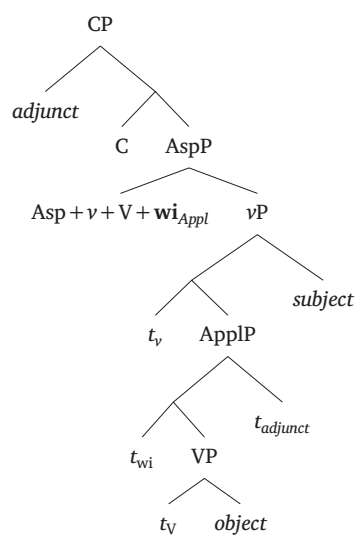

25 Can Pixabaj 2015: 163 reports that A'-extraction from the nominalized complement of certain verbs results in a single wi appearing on the verb that selects for the nominal. These data are identical in Patzún Kaqchikel, modulo the optionality:

(i) Extraction from a nominalization in Patzún Kaqchikel
a. Xta Telma $x-\varnothing-\varnothing$-mestaj $\quad r$-ya-ik $\quad$ ri medy pa $r$-achoch.
CLF Telma com-B3s-A3s-forget A3s-leave-NMLZ DET money PREP A3s-house
'Telma forgot to leave the money at her house.'
b. Ankuchi $x-\varnothing-\varnothing$-mestaj (wi) r-ya-ik ri medy?
where COM-B3s-A3s-forget (FP) A3s-leave-NMLZ DET money
'Where did she forget to leave the money?'
c. *Ankuchi $x-\varnothing-\varnothing$-mestaj wi r-ya-ik wi ri medy?
d. *Ankuchi $x-\varnothing-\varnothing$-mestaj r-ya-ik wi ri medy?

In the example above, the A3s marker is dropped. This is a property of Patzún Kaqchikel, where that marker can be dropped if the set в marker is also 3s; Patal Majzul et al. 2000: 69. We do not discuss these data in-depth, since they can be handled straightforwardly: the base copy is substituted by wi (a verbal clitic), so wi attaches to the only possible verbal host. 
An approach of this nature predicts that a single instance of wi should appear in long-distance extraction, possibly in the embedded clause. However, this prediction is incorrect, as shown before. Low-adjunct extraction from an embedded CP triggers a fronting particle on both embedded and matrix verbs in K'iche' and Patzún Kaqchikel (modulo the optionality in the latter).

The behavior of the fronting particle is therefore unexpected under the applicative head analysis: we would not predict multiple applicative heads to surface in any context. Beyond the empirical picture, however, theoretical concerns also arise. As we have discussed before, the fronting particle cannot co-occur with any in-situ adjunct. Furthermore, if the fronting particle is an applicative head, the fact that it appears in the matrix clause in cases of long distance extraction is mysterious (cf. (17) and (18)). ${ }^{27}$

To summarize, the empirical inadequacy and conceptual complications with this type of analysis lead us to conclude that the fronting particle does not instantiate the applicative head.

\subsection{THE FRONTING PARTICLE IS NOT A RESUMPTIVE PRONOUN}

Resumptive pronouns are pronouns in the tail position of a chain that is created via movement or through base generation complemented with another mechanism (Ross 1967; Chomsky 1977; Shlonsky 1992; Boeckx 2003; Sichel 2014). The precise analysis of a resumptive pronoun is immaterial to the point we will make here. Let us illustrate with modern Arabic, a language that has both a gap strategy and a resumptive strategy for wh-extraction. The resumptive pronoun is a verbal clitic:

Modern Arabic: gap strategy (Adapted from Alotaibi \& Borsley 2013)

?ayy-a T-tullaab-i qaabala l-qaa?id-u?

which-Acc the-students-Gen met.3sg.m the-leader-nOM

'Which of the students has the leader met?'

Modern Arabic: resumptive strategy (Adapted from Alotaibi \& Borsley 2013)

?ayy-u T-tullaab-i qaabala-hum l-qaa? id-u?

which-Nom the-students-GEN met.3sG.M-them the-leader-NOM

'Which of the students has the leader met?'

This analysis would propose, then, that wi is a resumptive element that occupies the tail of an A'-chain. ${ }^{28}$ 
(43)
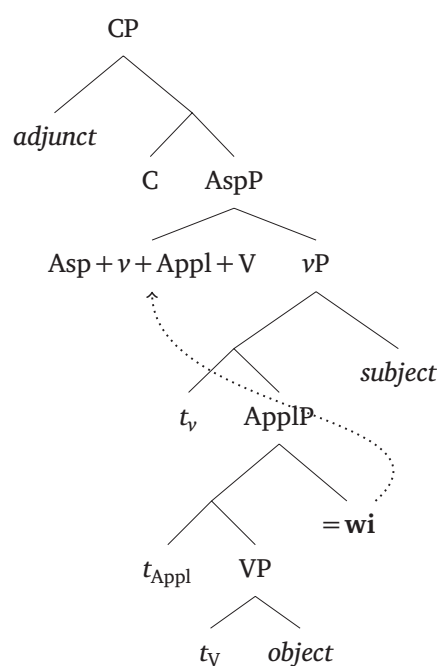

Let us move to concrete predictions made by the resumptive pronoun analysis. With regards to long-distance extraction, this analysis predicts that the fronting particle will appear only in the clause from which an adjunct is extracted. This prediction is wrong. Remember that in long-distance extraction from a CP, the fronting particle appears in both embedded and matrix clauses, as shown previously.

Another prediction concerns islands. In languages such as Lebanese Arabic, resumptive pronouns ameliorate island effects, as seen below.

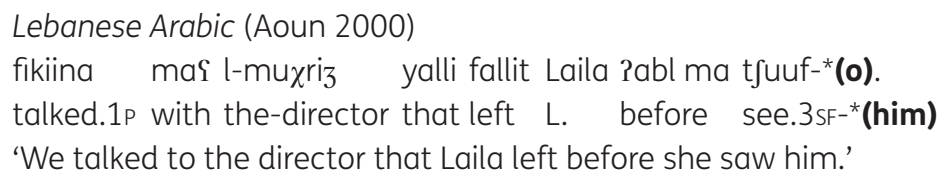

In contrast, the fronting particle doesn't alleviate island effects (see section 2, examples (15) and (16)). We can see, then, that the fronting particle does not exhibit the hallmarks of resumption.

Analyzing wi as a pronoun would also require it to be a pronoun that encompasses different kinds of phrases: wi would be a pronoun for instruments, locations, etc. However, we have been unable to find any evidence that wi functions as a run-of-the-mill pronoun. For example, wi cannot be used anaphorically. Consider (45), where an anaphoric use of wi is attempted:

$$
\begin{aligned}
& \text { Wi cannot be used as an anaphoric pronoun in Patzún Kaqchikel } \\
& \text { a. Context: Two friends are discussing where Pedro bought beans. } \\
& \text { b. Pa k'ayib'äl } x-\varnothing \text {-u-löq' wi pe? } \\
& \text { PREP market COM-B3s-A3s-buy FP DIR } \\
& \text { 'Did he buy them (beans) [at the market]? } \\
& \text { c. *Ja, x- Ø-u-löq' wi (pe), } \\
& \text { yes cOM-B3s-A3s-buy FP (DIR) } \\
& \text { Intended: 'Yes, he bought them there.' }
\end{aligned}
$$

Speaker A mentions the location of the buying, but speaker B cannot use wi anaphorically to refer back to that location.

The example given below shows that wi cannot be used as a deictic pronoun either. In the dialogue, the speaker answering the question attempts to refer to the location/saleswoman using wi, while pointing to the relevant referent. This is impossible.

(46) Wi cannot be used as a deictic pronoun in Patzún Kaqchikel

Context: Two sisters are walking by the marketplace. They pass by the flower stand where one of the two had bought flowers the day before.

$$
\begin{aligned}
& \text { A: Achike } x-\varnothing-a-b \text { 'än iwir? } \\
& \text { what com-B3s-A2s-do yesterday } \\
& \text { 'What did you do yesterday?' }
\end{aligned}
$$




\author{
B: $\quad$ X-Ø-in-löq' kotz'i'j. \\ сом-B3s-A1s-buy flowers \\ 'I bought flowers.' \\ B': 'X-Ø-in-löq' wi kotz'i’j. \\ COM-B3s-A1s-buy FP flowers \\ Intended: 'I bought flowers \{there/with her\}.' (pointing to the flower stand/the \\ saleswoman) \\ B': X-Ø-in-löq' kotz'i'j \{chi la'/r-k'in rija'\}. \\ COM-B3s-A1s-buy flowers \{PREP DEM /A3s-RN 3s \} \\ 'I bought flowers \{there / with her\}.' (pointing to the flower stand/the saleswoman) \\ $B^{\prime \prime \prime}$ : $\{$ Chi la' $/ r$-k'in rija' $\}$ x- $\varnothing$-in-löq' wi kotz'i'j. \\ \{PREP DEM /A3S-RN 3s \} COM-B3S-A1s-buy FP flowers \\ 'I bought flowers \{THERE/WITH HER\}.' (pointing to the flower stand/the saleswoman)
}

The way we interpret these results is that an analysis of wi as a pronoun would need to assume that it is a very strange pronoun: wi would be a pronoun that (i) cannot be used anaphorically or deictically and (ii) appears only in instances of $\mathrm{A}^{\prime}$-movement. In other words, it would be a pronoun that is used exclusively for resumption. However, there do not seem to be any languages that have a pronoun paradigm that is used exclusively for resumption (Boeckx 2008; see also McCloskey 2002 and Boeckx 2003). This in itself casts doubt on analyzing wi as a resumptive pronoun. Even if we assumed that wi is a typological outlier, though, we would still be faced with the challenges noted previously. We would need to propose that wi is a typologically extraordinary resumptive pronoun that also (i) cannot ameliorate island effects and (ii) occurs multiple times on the movement path of long-distance extraction from a CP. ${ }^{29}$

Given that these these behaviours are unexpected for (resumptive) pronouns, we find that this analysis has no obvious virtues and set it aside. ${ }^{30}$

\title{
4.3 THE FRONTING PARTICLE IS NOT THE SPELL-OUT OF A MOVEMENT TRIGGERING HEAD (WH-AGREEMENT)
}

The fronting particle could be analyzed as the spell-out of the $X^{0}$ that drives movement. ${ }^{31}$ This is equivalent to describing the fronting particle as the spell-out of wh-agreement.

Some languages have a dedicated morpheme that marks displacement to a focus position. In Kuria, focused elements surface preceded by a clitic which has been analyzed as the spellout of Foc ${ }^{0}$ (Landman \& Ranero 2018). Under this analysis, the difference between Kuria and K'ichean would be which constituent the movement trigger attaches to: in Kuria, as a proclitic on the displaced constituent, whereas in K'ichean, as an enclitic on the verb.

Kuria (Landman \& Ranero 2018)

a. Q: Where will Gati see the owl?

29 Furthermore, we will see in section 6 that some dialects of K'ichean have extended the use of wi to predicate fronting. If these data are the same phenomenon, then wi would need to be a pronoun that encompasses a subset of adjuncts, as well as phrases such as VP.

30 Another type of resumption-like phenomenon is what van Urk (2018) calls pronoun copying in Dinka. Pronoun copying occurs when a nominal is extracted and is analyzed as the result of partially deleting copies created by phrasal movement. In a nutshell, Dinka has a V2 requirement at the VP level that enforces the presence of a constituent in that position. Van Urk assumes that the VP is a phase and, thus, an intermediate landing site. Chain reduction deletes only a portion of the copy in Spec, $\mathrm{VP}$ and the resulting item satisfies the $V \mathrm{P}$ 's V2 requirement. The pronoun is basically the spell-out of the functional material remaining from NP-ellipsis (see also Postal 1969; Elbourne 2001 i.a.). Van Urk's analysis of pronoun copying and our analysis of wi have the same kind of flavor. There are crucial differences though. In Dinka, pronoun copying is proposed to be the result of partial deletion plus lexical insertion of pronominal material that exists in the language independently of extraction contexts. Assimilating wi insertion into a van Urk-style analysis runs into several problems, which are echoed in the main text here. First, as far as we know, there is no language that employs a single pronoun for a class of adjuncts, in our case low-adjuncts. Second, the formalization involving partial deletion cannot work for K'ichean. We would need to establish the portion of structure that is deleted in all of the moved adjuncts, such that the remnant structure in all of those cases is inserted as the same pronoun, which would not be part of the regular pronominal system. This is in contrast with Dinka, where the relevant particle is an independent pronoun. Van Urk's analysis might be on the right track for Dinka, but we see no possibility of extending his mechanism to the phenomenon here.

31 See Henderson 2008, Can Pixabaj 2009 and England 2009. For Henderson, the feature that spells-out as wi is the [Foc] on the moved element itself, making his analysis more similar to the applicative analysis we rejected in 4.1. Nevertheless, assessing the alternative we lay out here is important for our argumentation. 
b. N-ko mesa Gati umw-iti a-ra-maah-e. Foc-PREP table Gati 3-owl 3SA-FUt-See-FV

'Gati will see the owl on THE TABLE.'

Let us call this the movement trigger analysis and formalize it as follows: the fronting particle wi would be the spell-out of a head in the CP layer bearing an EPP/A'-feature and an applicative feature [APPL]. Under this analysis, the fronting particle would cliticize downwards onto the verb. ${ }^{32}$

(48)

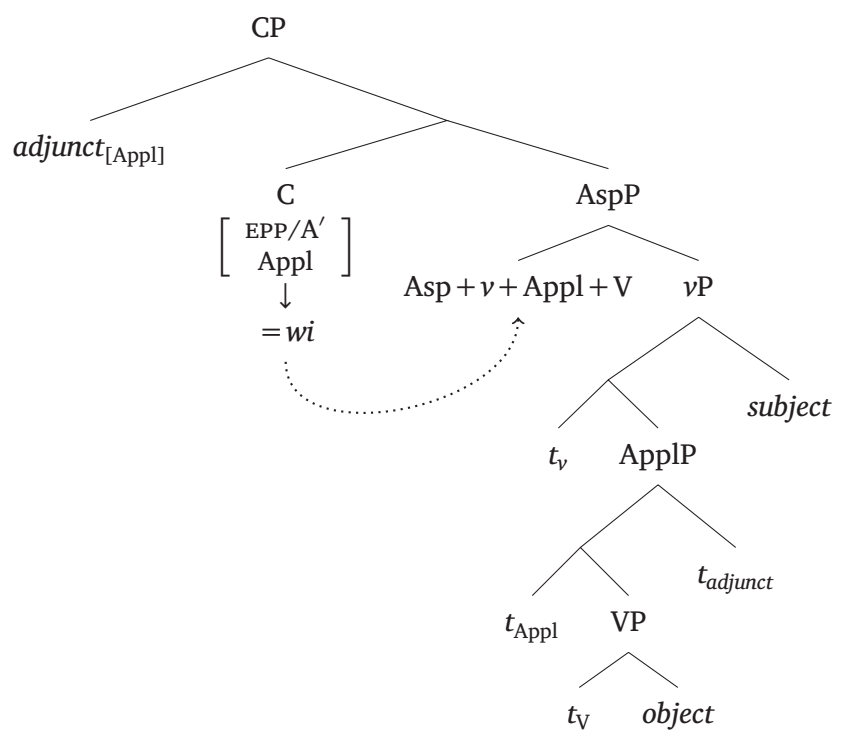

The movement-trigger analysis predicts that wi will appear in both embedded and matrix clauses upon long-distance extraction from a full CP. As we have seen previously, this prediction is correct. Therefore, the movement-trigger analysis, and our own, cannot be teased apart via this type of example.

However, extraction from reduced clauses favors our analysis. In these examples, wi appears only in the embedded clause (see examples (19) and (20)). The structure below shows why the movement trigger analysis makes the wrong prediction.

(49) Movement-trigger analysis (extraction from AspP); wrong prediction

The head in the $\mathrm{C}$ domain that triggers movement of the adjunct is spelled-out as wi and attaches downward to the verb in the clause.
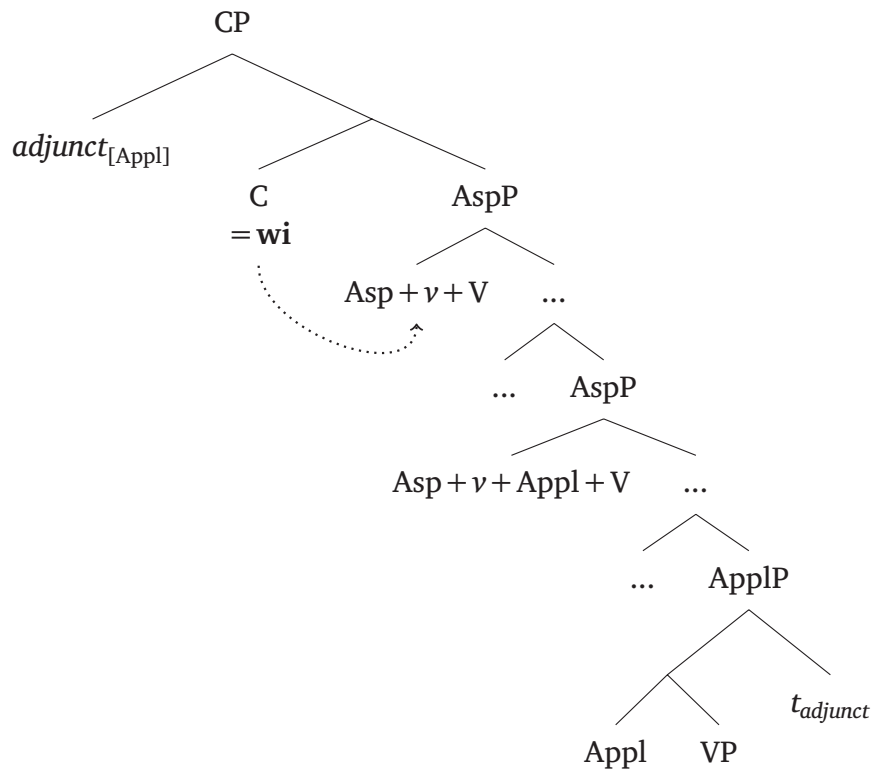

In extraction from AspP, there is no $\mathrm{C}^{0}$ in the embedded clause. The movement-trigger analysis predicts that, in the absence of a $\mathrm{C}^{0}$ in the embedded clause, the fronting particle would appear 
attached to the matrix verb (see (49)). However, this prediction is incorrect: the absence of $\mathrm{C}^{0}$ in the embedded clause bleeds the appearance of wi in the matrix clause. In contrast, our analysis makes the correct prediction, since the absence of an embedded $\mathrm{C}^{0}$ prevents the appearance of wi in the matrix clause because there is no intermediate movement step in Spec,CP (compare (49) with (37)).

Put differently, our analysis can account for the attested asymmetry between extraction from full versus reduced clauses, whereas the movement trigger/wh-agreement analysis predicts a different asymmetry. We therefore reject this analysis.

\subsection{THE FRONTING PARTICLE IS NOT PARALLEL TO THE AGENT FOCUS MORPHEME}

One could, in principle, entertain a connection between the phenomenon under study here and another characteristic of the K'ichean languages. Across K'ichean, ergative subjects cannot be $A^{\prime}$-extracted freely. In other words, these languages are syntactically ergative (Coon et al. 2014; Polinsky 2016; Aissen 2017b). In order to A'-extract a transitive subject, the verb must bear an Agent Focus (henceforth AF) morpheme..$^{33}$ The Patzún Kaqchikel data below illustrate the phenomenon:

$$
\begin{aligned}
& \text { AF in Patzún Kaqchikel } \\
& \text { a. 'Achike } \mathrm{x}-\varnothing \text {-u-tej nu-way? } \\
& \text { who com-B3s-A3s-eat A1s-tortilla } \\
& \text { Intended: 'Who ate my tortilla?' } \\
& \text { b. Achike } \mathrm{x}-\varnothing \text {-tj-o nu-way? } \\
& \text { who com-в3s-eat-AF A1s-tortilla } \\
& \text { 'Who ate my tortilla?' }
\end{aligned}
$$

The superficial parallel should be clear. Extraction of both ergative subjects and low adjuncts triggers the appearance of a special morpheme on the verb. Given this parallel, one could entertain the idea that the AF morpheme and the fronting particle are elements of the same type or at least have the same function. For example, Douglas et al 2017 posits that there is an extraction restriction on both ergative subjects and low adjuncts. The AF morpheme serves to circumvent the restriction on ergative subjects, while the fronting particle performs the same function for the restriction on low adjuncts.

There are too many accounts of syntactic ergativity and its interaction with AF for us to evaluate here (see Ordóñez 1995; Stiebels 2006; Deal 2016; Erlewine 2016; Aissen 2017b; Baier 2019; Coon et al. 2019; Ranero 2020). Since the focus of our paper is not syntactic ergativity or AF, we refrain from committing to any particular analysis of them. We will merely point out two crucial distributional asymmetries between the AF morpheme and the fronting particle which challenge any unified analysis. This challenge holds regardless of one's choice of analysis for AF and the source of syntactic ergativity.

The first asymmetry concerns long-distance extraction. Extraction of a transitive subject in Kaqchikel from a full CP requires the AF morpheme only in the embedded clause (Erlewine 2016). ${ }^{34}$ In contrast, wi can appear in both clauses, as we have observed before. ${ }^{35}$

$$
\begin{aligned}
& \text { Kaqchikel Agent Focus and long-distance extraction (Adapted from Erlewine 2016) } \\
& \text { a. Achike } n-\varnothing \text {-a-b'ij rat [chin } x \text {-oj-tz'et-ö roj ]? } \\
& \text { who INC-B3s-A2s-say 2sG [that COM-B1P-see-AF 1PL ] } \\
& \text { 'Who do you say saw us?' } \\
& \text { b. *Achike } n \text {-a-b’i-n rat [chin } x \text {-oj-tz'et-ö roj ]? } \\
& \text { who INC-B2s-Say-AF 2sG [that COM-B1P-see-AF 1PL ] } \\
& \text { c. *Achike } n \text { - } \varnothing \text {-a-b'ij rat [chin } x \text {-oj-r-tz'ët roj ]? } \\
& \text { who INC-B3s-A2s-say 2sG [that COM-B1P-A3s-see 1PL ] } \\
& \text { d. *Achike n-a-b'i-n rat [chin } \mathrm{x} \text {-oj-r-tz'ët roj ]? } \\
& \text { who INC-B2s-say-AF 2SG [that COM-B1P-A3s-see 1PL ] }
\end{aligned}
$$

33 The oblique antipassive voice can also be used (García Matzar \& Rodríguez Guaján 1997; López Ixcoy 1997; Heaton 2017).

34 The Kaqchikel data from Erlewine (2016) come from Patzún speakers as well.

35 We do not know how the AF morpheme behaves in long-distance extraction in K'iche'. 
The second asymmetry concerns the interaction of the fronting particle with different voices. The AF morpheme is in complementary distribution with voice morphemes (García Matzar \& Rodríguez Guaján 1997; López Ixcoy 1997; Aissen 2017b), which implies that it is an instance of voice. In contrast, the fronting particle can be combined with different voice morphemes, which implies that it is not an instance of voice. ${ }^{36}$

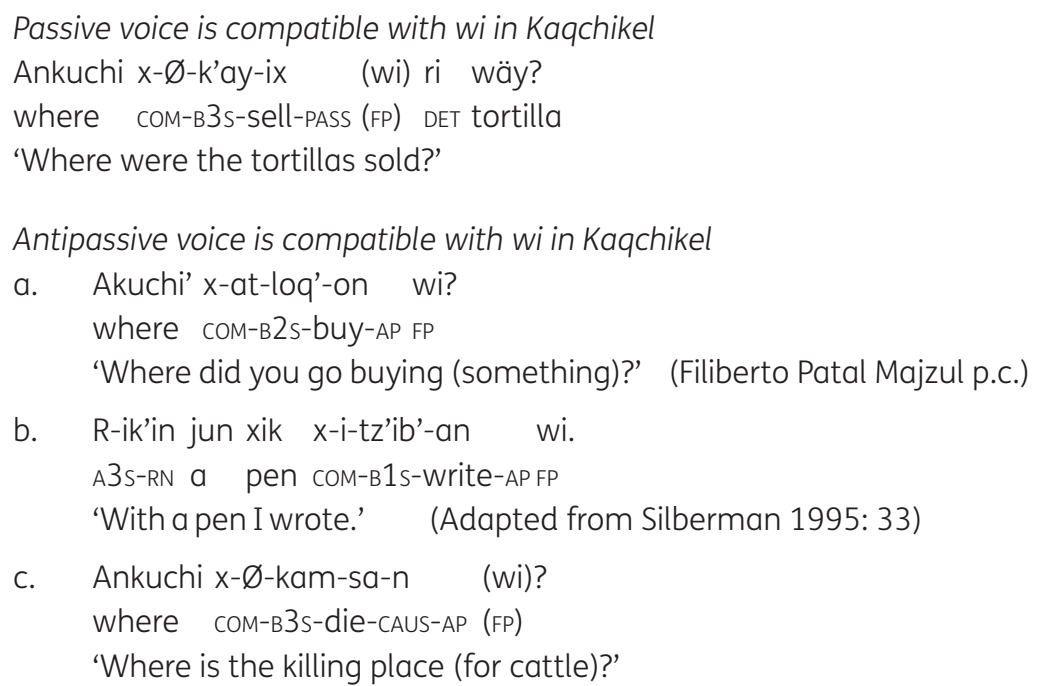

Given the two distributional asymmetries between the AF morpheme and the fronting particle, we conclude that they are elements of a different nature. As a result, we set aside any analysis that would conflate the two.

\section{THEORETICAL IMPLICATIONS}

Here, we discuss the broader theoretical implications of our analysis. First, we comment on the consequences of our approach for Chain Reduction. Second, we engage with proposals that claim that $C^{0}$ is not a phase head (den Dikken 2009; 2017), arguing that such conceptions of phasehood cannot account for the phenomenon discussed here. Finally, we show how the widely held view that both $C^{0}$ and $v^{0}$ are phase heads (Chomsky 2001) cannot account for our data either. We conclude that $\mathrm{C}^{0}$ is a phase head, while $v^{0}$ is not.

\subsection{CHAIN REDUCTION}

Our analysis has taken Chain Reduction to be applicable in two ways: a chain link is either (i) deleted or (ii) substituted by a particular morpheme.

In essence, then, all that is needed for linearization to succeed is for the copies to be rendered non-identical somehow. It has been often taken for granted that deletion is the only operation that reduces chains, resolving the linearization issue through the complete removal of phonological material of all but one chain link. ${ }^{37}$ We argue that limiting Chain Reduction to deletion is a stipulation based on a limited empirical sample. There is no a priori reason why deletion should be the only operation that feeds linearization. Instead, it seems plausible that the language faculty provides different strategies for resolving the issue at hand. One of these is deletion, which is observed in languages like English. Another strategy involves changing a chain link into a different element, what we have called Chain Reduction via Substitution. Specifically, substitution for a clitic like wi in K'ichean low-adjunct extraction renders each chain link distinct from each other: in a monoclausal structure, wi is non-identical to the topmost copy. In long-distance extraction from a CP, each verbal stem to which a wi cliticizes is distinct from the other as well (see Nunes 2004 on how the linearization process cannot access wordlevel domains).

36 The AF morpheme and the fronting particle cannot co-occur for independent reasons. The appearance of the AF morpheme implicates $A^{\prime}$-extraction of the external argument of a transitive verb and the fronting particle implicates the extraction of a low adjunct. 


\subsection{MUST BE A PHASE HEAD; LITTLE-V ${ }^{0}$ CANNOT BE A PHASE HEAD}

It has recently been argued in den Dikken 2009 and 2017 that $C^{0}$ is not a phase head. The author assesses the evidence in the literature for intermediate Spec,CP movement and argues that whenever Spec,CP is implicated in a movement dependency, an alternative analysis exists where such a position is not targeted. While we concur with den Dikken that the evidence for intermediate Spec,CP movement is sometimes problematic, proposing that $\mathrm{C}^{0}$ is not a phase head will fail to account for the K'ichean adjunct extraction phenomenon. This in itself casts doubt on the feasibility of a conception of phase heads that excludes $\mathrm{C}^{0}$. The crucial examples which adjudicate between den Dikken's proposal ( $\mathrm{C}^{0}$ is not a phase head) and the one advocated for in this article ( $\mathrm{C}^{\mathrm{O}}$ is crucially a phase head) involve long-distance movement, once again.

In section 4, we showed that the fronting particle is not an applicative head, a pronoun, a movement trigger, or an element akin to the AF morpheme. In order to assess den Dikken's approach versus our own, let us take for granted, then, that we are correct regarding the analysis of the fronting particle as the output of Chain Reduction via Substitution. Consider the K'iche' data below once again, involving extraction from a full CP:
a. Jas r-uuk' $x$ - $\varnothing$-aw-il wi chi $x$ - $\varnothing$-ki-qupi-j wi le ti'iij? 'With what did you see that they cut the meat?'
K'iche' long distance extraction from CP (Adapted from Can Pixabaj 2015: 166-167)
WH A3s-RN COM-B3s-A2s-see FP COMP COM-B3S-A3P-CUt-ACT FP DET meat
b. *Jas $r$-uuk' $x-\varnothing$-aw-il-o chi $x$ - $\varnothing$-ki-qupi-j wi le ti'iij? WH A3s-RN COM-B3s-A2s-see-ss COMP COM-B3s-A3P-CUt-ACT FP DET meat Intended: 'With what did you see that they cut the meat?'
c. *Jas r-uuk' $x-\varnothing$-aw-il wi chi $x$ - $\varnothing$-ki-qupi-j le ti'iij? WH A3s-RN COM-B3s-A2s-See FP COMP COM-B3S-A3P-CUt-ACT DET meat Intended: 'With what did you see that they cut the meat?'

As discussed before, this type of example shows one fronting particle per clause. We argued that the embedded wi is the output of Chain Reduction via Substitution on the lowermost link of the movement chain, while the matrix fronting particle is the output of Chain Reduction via Substitution on the chain link in embedded Spec,CP.

Now, let us take a den Dikken-style approach to phasehood, assuming that $\mathrm{C}^{0}$ is not a phase head, and attempt to make sense of the appearance of both fronting particles. If $\mathrm{C}^{0}$ is not a phase head, then the wi in the matrix clause could not be the chain link in intermediate Spec, CP, since such a position would not be an obligatory landing site in the path of movement. Let us assume with den Dikken, then, that $v^{0}$ is the only phase head. We would propose as a result that the matrix fronting particle is the output of Chain Reduction via Substitution of the chain link in matrix Spec,VP. The embedded fronting particle would be the output of Chain Reduction via Substitution of the chain link in embedded Spec,VP. We have thus derived the pattern in long distance extraction from CP under an approach where $\mathrm{C}^{0}$ is not a phase head (note that we illustrate with a right-branching structure for ease of exposition): ${ }^{38}$

$$
\begin{aligned}
& \text { Long-distance extraction from CP in K'iche'; only } v^{0} \text { is a phase head } \\
& \text { a. }\left[_ { \mathrm { CP } } \text { wh } \left[\mathrm { C } \left[_ { \mathrm { AspP } } \left[\mathrm { Asp } \left[_ { \mathrm { VP } } \mathbf { w h } \left[\mathrm { v } \left[_ { \mathrm { VP } } \left[\mathrm { V } \left[_ { \mathrm { CP } } \left[\mathrm { C } \left[_ { \mathrm { AspP } } \left[\mathrm { Asp } \left[_ { \mathrm { vP } } \mathbf { w h } \left[_ { \mathrm { VP } } \mathrm { EA } \left[\mathrm { V } \left[_{\mathrm{ApplP}} \mathbf{w h}[\mathrm{Appl}\right.\right.\right.\right.\right.\right.\right.\right.\right.\right.\right.\right.\right.\right.\right.\right. \\
& [\mathrm{vP} V][]][]][]]]]]]]]]] \rightarrow \\
& \text { b. } \quad\left[_ { \mathrm { CP } } w h \left[\mathrm { C } \left[_ { \mathrm { AspP } } \left[\mathrm { Asp } \left[_ { \mathrm { vP } } \mathbf { w i } \left[\mathrm { v } \left[_ { \mathrm { VP } } \left[\mathrm { V } \left[_ { \mathrm { CP } } \left[\mathrm { C } \left[_ { \mathrm { AspP } } \left[\mathrm { Asp } \left[_ { \mathrm { vP } } \mathbf { w i } \left[_ { \mathrm { vP } } \mathrm { EA } \left[\mathrm { v } \left[_ { \mathrm { ApplP } } \boldsymbol { \emptyset } \left[\mathrm { Appl } \left[_{\mathrm{VP}}\right.\right.\right.\right.\right.\right.\right.\right.\right.\right.\right.\right.\right.\right.\right.\right.\right.\right.
\end{aligned}
$$

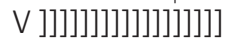

output of Chain Reduction

However, a den Dikken-style approach cannot explain the distribution of the fronting particle upon extraction from a reduced clause. Recall that these examples show a single fronting particle on the embedded verb:

38 A complication under this analysis is what to do with the base copy of the adjunct, which could, in principle, also be turned into a fronting particle. To streamline the discussion, we will assess an analysis where only intermediate copies in Spec, VP are reduced by substitution, whereas base copies are deleted. We invite the reader to calculate by themselves that having the base copy also undergo substitution would create additional problems for this alternative analysis (e.g., there would be two fronting particles in a monotransitive). 
K'iche' long distance extraction from AspP (Can Pixabaj 2015: 163)
a. Jas r-uuk' k- $\varnothing$-aw-aaj k- $\varnothing$-a-choy wi le sii'?
WH A3s-RN INC-B3s-A2s-Want INC-B3s-A2s-Cut FP FP firewood
'With what do you want to cut the firewood?'
b. *Jas r-uuk' k- $\varnothing$-aw-aaj wi k- $\varnothing$-a-choy le sii'?
WH A3s-RN INC-B3s-A2s-Want FP INC-B3s-A2s-Cut FP firewood
Intended: 'With what do you want to cut the firewood?'

Let us emphasize the difference between an example like (56) and one in which extraction occurs from a full CP. The difference involves the presence or absence of $\mathrm{C}^{0}$, and nothing else. Under our approach, the appearance of a single fronting particle on the embedded clause follows straightforwardly from the absence of $C^{0}$ : since there is no $C^{0}$, there is no phase, and no obligatory stopover. Movement thus proceeds in one fell swoop from base position to matrix Spec,CP. The single fronting particle in the embedded clause in (56) is the output of Chain Reduction via Substitution on the tail of the movement chain. For a den Dikken-style approach, though, these type of data pose a serious problem. If the fronting particle is the result of Chain Substitution of a chain link in $S p e c, v P$, then we would expect two fronting particles in (56) as well. In other words, manipulating the presence and absence of $C^{0}$ would not have any consequences for the distribution of the fronting particle, contrary to fact.

Note that we could not claim that examples like (56) display a single fronting particle because they involve a single vP layer, somehow shared between both clauses, instead of an independent VP layer in each clause. The reason is simple: in K'ichean, $v^{0}$ is the locus of ergative agreement (Aissen 2011; Coon et al. 2014; Coon 2016). If examples like the above involved a single vP layer, then we would predict that only one verb would display ergative agreement. However, this prediction is not borne out. Therefore, data like (56) are structurally identical in their $v P$ layers to examples involving extraction from a full CP. The only difference between the example types is the presence or absence of $\mathrm{C}^{0}$ in the embedded clause. We conclude then that the data here show that $C^{0}$ must be a phase head, contra den Dikken (2009; 2017). ${ }^{39}$

Perhaps, then, our approach is compatible with the broadly assumed stance that both $\mathrm{C}^{0}$ and $v^{0}$ are phases (see Citko 2014 for discussion). ${ }^{40}$ For this to work, we would need to complicate our rules of Chain Reduction such that they are context sensitive. Let us illustrate explicitly, assuming as we have so far that the base position of the relevant adjuncts is Spec,ApplP, which is above VP. Consider a simple monotransitive where a single wi appears:

Monotransitive extraction; both $C^{0}$ and $v^{0}$ are phase heads

$$
\begin{aligned}
& \text { a. } \quad\left[_{\mathrm{CP}} \mathbf{w h}\left[_{\mathrm{AspP}}\left[\mathrm{Asp}\left[_{\mathrm{VP}} \mathbf{w h}\left[_{\mathrm{VP}} \mathrm{EA}\left[\boldsymbol{v}\left[_{\mathrm{ApplP}} \mathbf{w h}\left[\mathrm{Appl}\left[_{\mathrm{VP}}[\mathrm{V}]\right]\right]\right]\right]\right]\right]\right]\right]\right] \\
& \text { b. } \quad\left[_{\mathrm{CP}} \mathbf{w h}\left[_{\mathrm{AspP}}\left[\operatorname{Asp}\left[_{v \mathrm{PP}} \mathbf{w i}\left[_{\mathrm{vP}} \mathrm{EA}\left[\mathrm{v}\left[_{\mathrm{ApplP}} \varnothing\left[\mathrm{Appl}\left[_{\mathrm{VP}}[\mathrm{V}]\right]\right]\right]\right]\right]\right]\right]\right]\right] \\
& \text { output of Chain Reduction }
\end{aligned}
$$

An approach taking $C^{0}$ and $v^{0}$ to be phase heads could assume that the copy in Spec,vP is substituted for wi. ${ }^{41}$ For this to work, we would need to modify our Chain Reduction rules so that the substitution of XP[APPL] by wi occurs only in the context of $V^{0}$ (applying to copies in Spec,VP). In other words, we would need to encode XP[APPL] $\rightarrow$ wi / _ $v$. Let us not delve into the question of whether encoding such context sensitivity is possible or conceptually desirable. Instead, let us focus on the data involving extraction from a reduced clause, to show why this approach is problematic.

Recall again that in these examples, only one fronting particle appears in the embedded clause. The problem that arises is significant. If we assume that there is a stopover in Spec,VP of the matrix clause, we are forced to propose that the copy in matrix Spec,vP does not trigger Chain Reduction via Substitution, unlike the copy in the embedded Spec,vP. If we did not encode

39 Embedding of reduced clauses shows a subject connectivity effect wherein the subject of the embedded clause must be identical to the subject or object of the matrix clause (Ajsivinac Sian 2007; Can Pixabaj 2015). We hypothesize that this connectivity results from a movement dependency (Hornstein 1999). We leave a more thorough investigation of the subject connectivity effect for future work, but restate that the connectivity effect could not arise due to a shared $\mathrm{VP}$ layer, given ergative agreement in both clauses.

40 Let us assume here for ease of exposition that all flavours of $v^{0}$ are phase heads (see Legate 2003).

41 Alternatively, one could assume that both the base copy and the Spec,vP copy are substituted for wi, but one wi is deleted in the morphophonology. See footnote 38. 
some difference between matrix and embedded vPs, we would expect two fronting particles here, contrary to fact:

$$
\text { Long-distance extraction from AspP in K'iche'; both } C^{0} \text { and } v^{0} \text { are phase heads }
$$

a. $\quad\left[_{\mathrm{CP}}\right.$ wh $\left[\mathrm{C}\left[_{\mathrm{AspP}}\left[\mathrm{AsP}\left[_{\mathrm{VP}} \mathbf{w h}\left[\mathrm{V}\left[_{\mathrm{VP}}\left[\mathrm{V}\left[_{\mathrm{AspP}}\left[\mathrm{Asp}\left[_{\mathrm{VP}} \mathbf{w h}\left[_{\mathrm{VP}} \mathrm{EA}\left[\mathrm{V}\left[_{\mathrm{ApplP}} \mathbf{w h}\left[\mathrm{Appl}\left[_{\mathrm{VP}}[\mathrm{V}\right.\right.\right.\right.\right.\right.\right.\right.\right.\right.\right.\right.\right.\right.\right.$ []]]]]]]]]]]]]]] $\rightarrow$

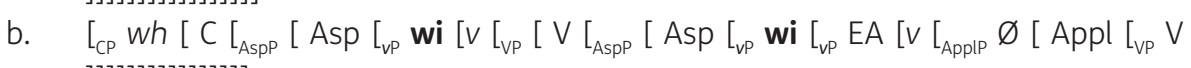
[]]][]]]][]]]]]]

\section{*unattested}

output of Chain Reduction

Therefore, we would need to specify the context for Chain Reduction via Substitution such that copies in embedded Spec,vPs trigger substitution by wi, but matrix Spec,vP copies (in contexts of extraction from AspP) do not. We know of no feasible way of formally encoding such a distinction without recourse to blunt stipulation. Therefore, we consider that an approach taking both $\mathrm{C}^{0}$ and $v^{0}$ to be phase heads cannot straightforwardly account for the K'ichean adjunct extraction phenomenon.

To summarize, the main problem for analyses that take only $v^{0}$, or both $C^{0}$ and $v^{0}$, as phase heads is that an explanation for the fronting particle generalization, which links the presence of $w i$ in the matrix clause to an overt complementizer in the embedded clause, is lost (see (21)).

Since the most elegant analysis of the phenomenon discussed here takes $\mathrm{C}^{0}$ as the only phase head in the clausal spine, we advocate for this position (see Keine 2017 for independent arguments from Hindi long-distance agreement in favor of the same conclusion). ${ }^{42}$ Put differently, the most explanatory account takes extraction from a reduced clause to occur in one fell swoop. There is no intermediate landing site at all, since there are no phase boundaries: $V^{0}$ is not a phase head, and there is no $\mathrm{C}^{0}$ in the embedded clause.

There are additional data that are fully consistent with our proposal that only $C^{0}$ is a phase head and $v^{0}$ is not. It has been argued that the phasehood of $v^{0}$ depends on its featural makeup (see Citko 2014 for discussion). In other words, $v^{0}$ only delimits a locality domain if it has certain properties (e.g., being the locus of ergative agreement or not). Consider, for instance, that Coon et al. 2014 tie the phenomenon of syntactic ergativity to the phasal status of transitive $v^{0}$, whose presence can be tracked by the appearance of ergative agreement (see footnote 42). For the phenomenon at hand, then, we might expect, that the distribution of the fronting particle would be impacted by manipulating $v^{0} s$ in the path of extraction. However, this is not the case: in extractions from a reduced clause, manipulating the matrix or embedded $v P$ does not affect the pattern we have described. Let us illustrate with Kaqchikel, since we presently have no parallel K'iche' data.

First, recall that extraction from AspP results in a single fronting particle in the embedded clause. In the example below, neither matrix nor embedded $v \mathrm{P}$ show ergative agreement. The matrix verb is a modal that takes AspP complements and only controls absolutive agreement, while the embedded verb is an intransitive: 43

$$
\begin{aligned}
& \text { Patzún Kaqchikel extraction from AspP } \\
& \text { a. Ankuchi } x \text { - } \varnothing \text {-tikï } \quad \mathrm{x} \text { - } \varnothing \text {-muxan (wi) rija'? } \\
& \text { where сом-в3s-be.able сом-в3s-swim (FP) 3s } \\
& \text { 'Where was she able to swim?' } \\
& \text { b. }{ }^{*} \text { Ankuchi } x \text { - } \varnothing \text {-tikir wi } x-\varnothing \text {-muxan wi rija'? } \\
& \text { where сом-B3s-be.able FP сом-B3s-swim FP 3s } \\
& \text { Intended: 'Where was she able to swim?' }
\end{aligned}
$$

42 Readers familiar with the Mayanist literature might wonder about syntactic ergativity in relation to the phasal status of a verbal head. Some authors tie the extraction restriction to the lower phase domain (e.g. Coon et al. 2014). There are proposals in the literature, however, that take syntactic ergativity in K'ichean to arise for reasons independent of the phasehood of $v^{0}$ (i.e. Erlewine 2016; but see Henderson \& Coon 2017) or due to ergative DPs moving too early (Assmann et al. 2015). We leave for future work an assessment of different proposals for syntactic ergativity in K'ichean in light of our proposal here.

43 We set aside how it is that modal verbs like matrix -tikïr do not control ergative agreement morphology. Our point is that manipulating little- $v^{0}$ flavors here does not change the pattern. 

c. *Ankuchi $x$ - $\varnothing$-tikir wi $x-\varnothing$-muxan rija'?
where сом-B3s-be.able FP сом-B3s-swim 3s
Intended: 'Where was she able to swim?'

The pattern remains the same. Let us now manipulate the embedded vP such that it controls ergative agreement. As shown below, the pattern is identical, regardless of this manipulation:

$$
\begin{aligned}
& \text { Patzún Kaqchikel extraction from AspP } \\
& \text { a. Ankuchi x-e-tikïr } \quad \mathrm{x} \text { - } \varnothing \text {-ki-löq' (wi) kotz'i'j? } \\
& \text { where сом-B3p-be.able сом-B3s-A3P-buy (FP) flowers } \\
& \text { 'Where were they able to buy flowers?' } \\
& \text { b. *Ankuchi } \quad x \text {-e-tikir wi } x \text { - } \varnothing \text {-ki-löq' wi kotz'i’j? } \\
& \text { where } \quad \text { сOM-B3P-be.able FP сом-B3s-A3P-buy FP flowers } \\
& \text { Intended: 'Where were they able to buy flowers?' }
\end{aligned}
$$

Conceivably, manipulating the matrix VP might lead to a different pattern regarding the behavior of wi. However, this is not the case either. In the example below, both matrix and embedded vPs control ergative agreement, but the pattern is identical.

$$
\begin{aligned}
& \text { Patzún Kaqchikel extraction from AspP } \\
& \text { a. Achoj k'in } x-\varnothing \text {-u-rayij } \quad x-\varnothing \text {-u-tz'ët (wi) xta Ixchel? } \\
& \text { WH RN COM-B3s-A3s-desire COM-B3s-A3s-see (FP) CLF Ixchel } \\
& \text { 'Who did she have the desire to see Ixchel with?' } \\
& \text { b. *Achoj k'in } x-\varnothing \text {-u-rayij wix- } \varnothing \text {-u-tz'ët wi xta Ixchel? } \\
& \text { WH RN COM-B3s-A3s-desire FP COM-B3s-A3s-see FP CLF Ixchel } \\
& \text { Intended: 'Who did she have the desire to see Ixchel with?' } \\
& \text { c. *Achoj k'in } x-\varnothing \text {-u-rayij wi } x \text { - } \varnothing \text {-u-tz'ët xta Ixchel? } \\
& \text { WH RN COM-B3s-A3s-desire FP COM-B3s-A3s-see CLF Ixchel } \\
& \text { Intended: 'Who did she have the desire to see Ixchel with?' }
\end{aligned}
$$

In a nutshell, the manipulation of vPs does not change the pattern when extracting from AspPs. If the results were otherwise we would have had evidence that $v^{0}$ is involved the distribution of the fronting particle. Any analysis which took the appearance of wi to be tied to the phasehood of $V^{0}$ would need to explain why manipulation of the CP domain changes the distribution of wi, but the featural make-up of $v^{0}$ is irrelevant. This leads us to conclude that our approach is superior.

To summarize this section, the K'ichean adjunct extraction phenomenon adds to the existing empirical evidence that $v^{0}$ is not a phase head (Keine 2017). Note that we are not claiming that Spec,vP can never, in any language, be a possible stopover in $\mathrm{A}^{\prime}$-extraction. Rather, since the theory of phases is about obligatory intermediate movement steps, we conclude that the phenomenon here argues against such obligatory stopovers in the verbal domain. ${ }^{44}$

\section{FUTURE RESEARCH}

In this section, we lay out areas for future research. First, we describe data that do not follow straightforwardly from our proposal, suggesting possible analyses. We then show the range of microvariation attested in the phenomenon, arguing that it can be captured via our proposal.

Even though wi is canonically tied to low-adjunct extraction, several authors have reported other functions (Henderson 2008 for Kaqchikel; Can Pixabaj 2009 and Velleman 2014 for K'iche').

Consider first the following examples: 45

44 In other words, we are not dismissing previous arguments for intermediate movement in Spec,vP (e.g. Legate 2003, Sauerland 2003, Henry 2012, as well as van Urk 2018). However, our proposal here suggests, at least, that a broader re-evaluation is needed. Note, nevertheless, that Legate and Sauerland only show that Spec, vP is a possible stopover point in English, not an obligatory one. We leave as an open question what determines whether $\mathrm{Spec}, \mathrm{VP}$ can be a possible stopover in some languages but not others.

45 Velleman transcribes wi as polarity focus. 
a. X-Ø-in-löq' wi ri äk'.

СOM-B3s-A1s-buy FP DEM chicken

b. X-i-samäj wi.

COM-B1s-work FP

'I WORKED (nothing else).'

(63) K'iche' polarity focus (Adapted from Velleman 2014: 42)

Pero a're', xaq si na k-u-maj=ta=wi ki-wach.

but $3 P$ just really NEG1 INC-A3s-begin=NEG $2=F P$ A3s-face

'But they really just did not like it.'

Here, wi is not tied to $\mathrm{A}^{\prime}$-extraction of a low adjunct. ${ }^{46}$ One possibility would be that the entire predicate is substituted by wi. This analysis would require further refinements in the Chain Reduction procedure in order for VP copies to also undergo substitution.

Consider now examples reported by González (2016) for Sololá Kaqchikel and Can Pixabaj (2009) for K'iche', where the fronting particle does not appear after the verb. Rather, the fronting particle appears directly after a (presumably fronted) temporal adverb or nominal. ${ }^{47}$

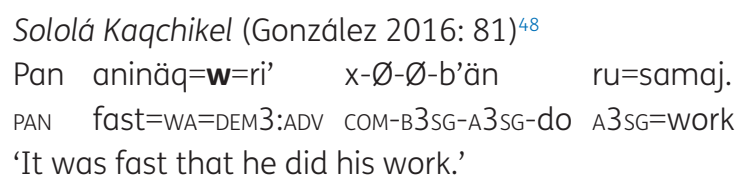

K’iche' (Can Pixabaj 2009)

Achijaab' wi la' k-e-qaasa-n r-ech le che'.

workers FOC DEM INC-B3P-CUt-AP A3S-RN DET tree

'It should be men who should cut down the tree.' (as opposed to children, women, boys who could not do that)

Though these examples appear difficult to reconcile with our proposal as it stands, we can offer some analytical direction. The presence of the demonstratives ri' in the Sololá Kaqchikel example and la' in the K'iche' example suggests that these structures are clefts of some sort. If so, we hypothesize that in both cases, the fronting particle is not marking adjunct or nominal extraction. Rather, and in a similar fashion to the first examples discussed in this section, there exists some predicate focus associated with the cleft structure. The study of clefts in K'ichean requires more careful research, in order to test our hypothesis.

Finally, Henderson (2008) reports Kaqchikel examples where long-distance extraction from CP triggers only a single wi in the embedded clause (examples 32-36; Silberman 1995 shows similar examples for some speakers). ${ }^{49}$ Henderson, however, does not show that having multiple wi particles is impossible, so the full pattern is unclear. A possibility, nevertheless, is that the dialect discussed by Henderson should not be analyzed in the same manner as Patzún Kaqchikel. What this illustrates is that a unified analysis of all reported variation in the fronting particle might be too ambitious, but we hope to return to this issue in the future.

At this juncture, then, let us turn to microvariation more broadly. The fronting particle occurs in all K'ichean languages: Kaqchikel (including colonial Kaqchikel; Matsumoto 2015), K'iche', Tz'utujil (San Juan, San Pedro, and Santiago dialects: Dayley 1985; García Ixmatá 1997; Mendes \& Ranero 2017), Sipakapense (Barrett 1999; 2008), Sakapulteko (DuBois 1981; Mó Isém 2007),

46 Examples like these were rejected by all of our Patzún Kaqchikel consultants, but since they have been reported for some dialects, providing an analysis consistent with ours is desirable.

47 We have also been unable to replicate these examples in Patzún Kaqchikel.

48 We suspect the word pan in the example is a typo, but leave the example as reported.

49 An anonymous reviewer points out that this kind of example is also attested in corpora of the Santiago Sacatepéquez dialect. We leave for the future an investigation of corpora for Patzún Kaqchikel, which would shed some light on the use of wi. Also, the same reviewer notes that looking at corpora might show whether there is some prosodic constraint regulating when wi is dropped. For instance, it might be the case that it is most often dropped in medial position, as opposed to phrase final position. 
Uspanteko (Can Pixabaj 2007), Q'eqchi' (Berinstein 1984; Caz Cho 2000), and Poqom (Malchic Nicolás et al. 2000). ${ }^{50}$ There are two parameters governing the microvariation: (i) Whether the fronting particle is required, optional, or banned, and (ii) which adjuncts trigger the fronting particle.

Let us turn to (i) first. We are not the first to report the existence of optional uses of wi in Kaqchikel. ${ }^{51}$ Silberman 1995: 41 shows optional uses of wi for a Tecpán Kaqchikel speaker and Patal Majzul et al. 2000: 144-145 reports optional uses of wi (without specifying the dialect).

In contrast, wi has been reported as obligatory by Henderson (2008) and García Matzar \& Rodríguez Guaján (1997). Henderson worked primarily with speakers from Santiago Sacatepéquez, complemented with data from San Juan Comalapa and Patzicía (Robert Henderson p.c.). García Matzar \& Rodriguez Guaján are native speakers of the San Andrés Semetabaj and Tecpán dialects respectively. There exist, then, Kaqchikel dialects where the particle is obligatory, in a similar vein to the K'iche' data discussed previously.

Moreover, our fieldwork and prior literature show that some Kaqchikel speakers do not use wi at all. Our consultants from Tecpán reject wi:

$$
\begin{aligned}
& \text { Tecpán Kaqchikel: no fronting particle } \\
& \text { a. Akuchi' } x \text { - } \varnothing \text {-tzopin ('wi) ri Lolmay? } \\
& \text { where cOM-B3s-jump ( }{ }^{*} F \text { P) DET Lolmay } \\
& \text { 'Where did Lolmay jump?' } \\
& \text { b. Choj k'in } x-\varnothing \text {-tzopin ( }{ }^{*} \text { wi) ri Ixchel? } \\
& \text { WH RN COM-B3s-jump ( }{ }^{*} F \text { P) DET Ixchel } \\
& \text { 'What did Ixchel jump with?' } \\
& \text { C. R-ik'in ri k'an } x-\varnothing \text {-tzopin ('wi). } \\
& \text { A3S-RN DET rope cOM-B3s-jump ( }{ }^{*} F \text { ) } \\
& \text { 'Ixchel jumped [with the rope] }]_{F} \text { ' }
\end{aligned}
$$

As we noted before, Silberman worked with Tecpán consultants who employed the particle optionally. Conversely, Rodríguez Guaján is from Tecpán, yet reports the particle as being obligatory. We therefore observe that, even within the same dialect, descriptions vary regarding the use of wi. ${ }^{52}$ The existence of dialects that do not employ wi had been noted elsewhere by Assmann et al. 2015. ${ }^{53}$ Additionally, Patal Majzul et al. 2000: 145 show that the Santo Domingo Xenacoj dialect does not employ the particle.

In a nutshell, there is significant variation regarding the obligatoriness of wi across Kaqchikel dialects. We propose that this aspect of the variation should not be modelled via parameters encoded via the presence/absence of features on functional heads (Hagit Borer's conjecture: Borer 1984). Rather, the microvariation we observe in this respect can be relegated to the PF component. Within the domain of low adjunct extraction, some grammars recur to Chain Reduction via Deletion across the board (no wi). Other speakers acquire a system wherein substitution applies optionally, preempting the application of the elsewhere deletion rule just in case substitution applies. The system where substitution applies optionally can be acquired through positive evidence in the input showing wi in some tokens of a specific construction. Still, other speakers acquire a system where Chain Reduction via Substitution is obligatory. As a result, these speakers apply substitution to XP[APPL] without exception, resulting in the obligatory fronting particle. Our approach to modelling microvariation falls in line, then, with work that seeks to place variation within the PF component (Boeckx 2016). We find this result to be desirable on a conceptual level, since an aspect of the microvariation associated with an apparently syntactic phenomenon need not be attributed to variation within the syntax itself.

50 There is a similar phenomenon in some dialects of Mam, which is not K'ichean (Perez Vail 2014 for Cajolá Mam and England 1989 for Tacaná and Ostuncalco Mam). The fronting particle in Mam is not a cognate of wi.

51 For reasons of space, we do not discuss microvariation in K'iche'. Par Sapón \& Can Pixabaj (2000): 167 report that $w i$ is absent in some varieties and optional in others (without specifying any details).

52 The difference could be a result of diachronic change, rather than there existing three different grammars within the Tecpán area today. However, our analysis can handle this type of variation, if it were indeed present within a single community.

53 The authors, however, are not explicit regarding their informants' hometowns. 
The other component of the microvariation involves which XPs trigger the fronting particle. For example, Henderson (2008) reports that benefactive extraction does not trigger wi in Kaqchikel, but it does for our Patzún informants: ${ }^{54}$

$$
\begin{aligned}
& \text { Patzún Kaqchikel: benefactives trigger wi } \\
& \text { Achoj ru-ma x- } \varnothing \text {-samäj (wi) ri Daniel? } \\
& \text { WH A3s-RN COM-B3s-work (FP) DET Daniel } \\
& \text { 'Who did Daniel work for?' }
\end{aligned}
$$

Additionally, Patal Majzul et al. (2000): 150 show that instrumental extraction in the San Antonio Palopó and San José Poaquil dialects does not trigger wi. This contrasts with the reports in Henderson 2008, Garciá Matzar \& Rodríguez Guaján 1997, and our own. ${ }^{55}$

The question of how to model this aspect of the variation is simple under our analysis. The variation arises from speakers' categorization of XPs during the acquisition process. In other words, when acquirers categorize the space of adjunct XPs, only some are analyzed as introduced by high applicatives (thus bearing [APPL]). In the mature grammar, whichever XPs were analyzed as XP[APPL] serve as input to Chain Reduction via Substitution. We expect microvariation to arise here, since the mature grammar will be wholly dependent on the input. In other words, variable input regarding extraction of the relevant XPs will result in (i) unstable and (ii) minutely different grammars. Under our account, the analysis of wi as the output of Chain Reduction via Substitution remains constant across dialects, but differences arise due to the acquisition process. For example, imagine that a child is not exposed to any benefactive extraction data with wi. We would expect that she would then fail to identify the benefactive as a high applicative. In other words, benefactives would not trigger wi in her grammar, leading thus to a minutely different grammar from others.

\section{CONCLUSION}

We have shown that deletion of a subset of copies in a movement chain is not the only strategy available to deliver a linearizable string. Through the lens of low-adjunct extraction in a subset of K'ichean (Mayan) languages, we proposed that copies can also undergo substitution by a particular morpheme (here wi). This substitution is as successful as deletion in circumventing a linearization paradox.

The empirical domain explored here has also shed light on the nature of movement and phases. Following work by Can Pixabaj (2015), we showed that the behavior of the fronting particle in the context of long-distance extraction depends on the presence or absence of $\mathrm{C}^{0}$ in the complement clause from which movement is launched. We showed, furthermore, that an analysis that takes $\mathrm{C}^{0}$ to be the only phase head in the clausal spine can account for the distribution of the fronting particle most elegantly. This proposal was defended via our rejection of analyses claiming that $C^{0}$ is not a phase head (den Dikken 2009; 2017) and proposals where both $C^{0}$ and $v^{0}$ are phase heads (Chomsky 2001). In arriving at our conclusion, we have contributed to recent arguments that $C^{0}$ delimits a cyclic domain, whereas $v^{0}$ does not (Keine 2017).

We also showed that certain recalcitrant data could follow from our approach, pending future work. Most importantly, however, we showed that microvariation in the phenomenon can be straightforwardly modelled via our analysis. This is a significant result, given the range of reports regarding the distribution of the fronting particle across K'ichean languages and dialects.

Naturally, our work here is not done. Whereas this particular phenomenon points in one direction, there are arguments in the literature which rely crucially on the phasehood of $v^{0}$. The question that arises as we conclude is how to reconcile assumptions that explain independent empirical phenomena, but which are broadly incompatible. We leave this for future research, but hope that our particular approach will entice further work into these issues, most saliently through the lens of hitherto under-explored empirical domains.

\footnotetext{
54 Note that Pylkkänen (2002) assumes that benefactives can be high (Chaga) or low (English), depending on the language. We would expect such microvariation to exist in K'ichean as well, with the availability of wi tracking this difference, resulting in subtle semantic differences. 


\section{ABBREVIATIONS}

$\mathrm{A}=$ set $\mathrm{A}$ agreement (ergative/genitive), $\mathrm{ACC}=$ accusative, $\mathrm{ACT}=$ active, $\mathrm{ADV}=$ adverbial, $\mathrm{APPL}=$ applicative, AF = agent focus, AP = antipassive, ASP = aspect, B = set B agreement (absolutive), CAUS = causative, $\mathrm{CLF}=$ classifier, $\mathrm{COM}=$ completive aspect, $\mathrm{COMP}=$ complementizer, $\mathrm{DEM}=$ demonstrative, $\mathrm{DET}=$ determiner, $\mathrm{DIR}=$ directional, $\mathrm{EMPH}=$ emphatic marker, $\mathrm{ERG}=$ ergative, $\mathrm{EXS}$ $=$ existential, $\mathrm{EXT}=$ extraction, $\mathrm{FOC}=$ focUS, $\mathrm{FP}=$ fronting particle, $\mathrm{FUT}=$ future, $\mathrm{FV}=$ final vowel, GEN = genitive, $\mathrm{INC}=$ incompletive, $\mathrm{INST}=$ instrumental, $\mathrm{LER}=$ left-edge resumptive, $\mathrm{M}=$ masculine, MEAS = measurement, MOV $=$ movement marker, NOM $=$ nominative, $\mathrm{P}=$ plural, PASS $=$ passive, PREP $=$ preposition, $\mathrm{PRF}=$ perfective, $\mathrm{PST}=$ past, $\mathrm{REF}=$ reflexive, $\mathrm{RN}=$ relational noun, $\mathrm{S}=$ singular, $\mathrm{SBJ}$ $=$ subject, $\mathrm{SS}=$ status sufix, $\mathrm{SA}=$ subject agreement, $\mathrm{TR}=$ transitive, $\mathrm{VN}=$ verbal noun. In the Chichewa and Kuria examples, number indicates noun class.

\section{ACKNOWLEDGEMENTS}

Authors share first-authorship and are listed alphabetically. We acknowledge financial support from NSF grants BCS \#1563129 and BCS \#1619857 to Maria Polinsky, and a CAPES grant to Gesoel Mendes \#0652-14-8 (PhD abroad). We wish to thank all of our language consultants, in particular Rosario Ramírez (Santiago Tz'utujil), Victoria Socop, Odilia Socop, Marta Julia Güitz and María Pérez Güitz (Tecpán Kaqchikel), Gilda Ixén, María Luisa Itzol (RIP), Glenda Leticia Chuluc, Imelda Ixén, and Victoriana Sipac (Patzún Kaqchikel). We thank Maria Polinsky, Omer Preminger, and Pedro Mateo Pedro for their support during the development of this project, as well as all the participants in the summer 2016 trip to the UMD field station in Guatemala. Thank you to the audiences at FAMLi4, SSILA 2017, BLS 43, and CamCoS 6 for feedback, especially Judith Aissen, B'alam Eladio Mateo Toledo, Jamie Douglas, Michelle Sheehan, Nora England, Robert Henderson, Amy Rose Deal, Michael Diercks, Paulina Lyskawa, Michelle Yuan, Juan Uriagereka, Norbert Hornstein, Howard Lasnik, and in particular Telma Can Pixabaj. Finally, thank you to three anonymous reviewers for detailed comments that substantially improved the paper. All errors are our own. Funding for open access was provided by the UMD Libraries' Open Access Publishing Fund.

\section{COMPETING INTERESTS}

The authors have no competing interests to declare.

\section{AUTHOR AFFILIATIONS}

Gesoel Mendes (D) orcid.org/0000-0003-1564-1970

University of Maryland, 1401 Marie Mount Hall, University of Maryland, College Park, MD, US

Rodrigo Ranero (D) orcid.org/0000-0001-8797-6695

University of Maryland, 1401 Marie Mount Hall, University of, Maryland, College Park, MD, US

\section{REFERENCES}

Aissen, Judith. 1992. Topic and focus in Mayan. Language 68(1). 43-80. DOI: https://doi.org/10.1353/ lan.1992.0017

Aissen, Judith. 2011. On the syntax of Agent Focus in K'ichee'. In Kirill Shklovsky, Pedro Mateo Pedro \& Jessica Coon (eds.), Proceedings of Formal Approaches to Mayan Linguistics I (MIT Working Papers in Linguistics Vol. 63), 1-16. Cambridge, MA: MITWPL.

Aissen, Judith. 2017a. Complement clauses. In Judith Aissen, Nora England \& Roberto Zavala (eds.), The Mayan Languages (Routledge Language Families), 259-292. New York: Routledge. DOI: https://doi. org/10.4324/9781315192345-10

Aissen, Judith. 2017b. Correlates of ergativity in Mayan. In Jessica Coon, Diane Massam \& Lisa Travis (eds.), The Oxford Handbook of Ergativity. Oxford: Oxford University Press. DOI: https://doi. org/10.1093/oxfordhb/9780198739371.013.30

Aissen, Judith, Nora England \& Roberto Zavala (eds.). 2017. The Mayan languages. London: Routledge. DOI: https://doi.org/10.4324/9781315192345

Ajsivinac Sian, Juan. 2007. Complementación en Kaqchikel. Paper presented at Taller de Complementación II by OKMA/CIESAS. 
Alotaibi, Mansour \& Robert D. Borsley. 2013. Gaps and resumptive pronouns in modern standard arabic. In Stefan Mueller (ed.), Proceedings of the 20th international conference on Head-Driven Phrase Structure Grammar, 6-26. Stanford, CA: CSLI Publications.

Aoun, Joseph. 2000. Resumption and Last Resort. D.E.L.T.A 16. 13-43. DOI: https://doi.org/10.1590/S010244502000000300001

Assmann, Anke, Doreen Georgi, Fabian Heck, Gereon Müller \& Philipp Weisser. 2015. Ergatives move too early: On an instance of opacity in syntax. Syntax 18(4). 343-387. DOI: https://doi.org/10.1111/synt.12034

Baier, Nicholas. 2019. Anti-agreement. Berkeley, CA: University of California dissertation.

Baker, Mark C. 1988. Incorporation: A theory of grammatical function changing. Chicago, IL: University of Chicago Press.

Barrett, Rusty. 1999. A grammar of Sipakapense Maya. Austin, TX: University of Texas dissertation.

Barrett, Rusty. 2008. Linguistic differentiation and Mayan language revitalization in Guatemala. Journal of Sociolinguistics 12(3). 275-305. DOI: https://doi.org/10.1111/j.1467-9841.2008.00368.x

Bastos-Gee, Ana Claudia. 2009. Topicalization of verbal projections in Brazilian Portuguese. In Jairo Nunes (ed.), Minimalist essays on Brazilian Portuguese syntax, 161-189. Amsterdam: John Benjamins. DOI: https://doi.org/10.1075/la.142.11bas

Berinstein, Ava. 1984. Evidence for Multiattachment in K'ekchi Mayan. Los Angeles, CA: University of California dissertation.

Boeckx, Cedric. 2003. Islands and chains: Resumption as stranding. Amsterdam: John Benjamins. DOI: https://doi.org/10.1075/la.63

Boeckx, Cedric. 2008. Bare syntax. Oxford: Oxford University Press.

Boeckx, Cedric. 2016. Considerations pertaining to the nature of logodiversity. In Luis Eguren, Olga Fernández-Soriano \& Amaya Mendikoetxea (eds.), Rethinking parameters, 64-104. Oxford: Oxford University Press. DOI: https://doi.org/10.1093/acprof:oso/9780190461737.003.0003

Borer, Hagit. 1984. Parametric syntax. Dordrecht: Foris. DOI: https://doi.org/10.1515/9783110808506

Bošković, Željko \& Jairo Nunes. 2007. The copy theory of movement: A view from PF. In Norbert Corver \& Jairo Nunes (eds.), The copy theory of movement, 13-74. Amsterdam: John Benjamins. DOI: https:// doi.org/10.1075/la.107.03bos

Can Pixabaj, Telma. 2007. Jkemiik Yoloj li Uspanteko: Gramática Uspanteka. Guatemala: Editorial Cholsamaj.

Can Pixabaj, Telma. 2009. The particle wi in K'ichee': A focus marker. Paper presented at SSILA.

Can Pixabaj, Telma. 2015. Complement and purpose clauses in K'iche'. Austin, TX: University of Texas dissertation.

Can Pixabaj, Telma \& Nora England. 2011. Nominal topic and focus in K’ichee'. In Rodrigo Gutiérrez-Bravo, Line Mikkelsen \& Eric Potsdam (eds.), Representing language: Essays in honor of Judith Aissen, 15-30. Santa Cruz: Linguistics Research Center, UC Santa Cruz.

Can Pixabaj, Telma A. 2017. K'iche'. In Judith Aissen, Nora England \& Roberto Zavala (eds.), The Mayan languages (Routledge Language Families), 461-499. New York: Routledge. DOI: https://doi. org/10.4324/9781315192345-18

Caz Cho, Sergio. 2000. Xtz'ilb'al rix li aatinak sa' Q'eqchi': Informe de variación dialectal en Q'eqchi'. Guatemala: Editorial Cholsamaj.

Cheng, Lisa Lai-Shen \& Luis Vicente. 2013. Verb doubling in Mandarin Chinese. Journal of East Asian Linguistics 22(1). 1-37. DOI: https://doi.org/10.1007/s10831-012-9095-6

Chomsky, Noam. 1977. On WH-Movement. In Peter W. Culicover, Thomas Wasow \& Adrian Akmajian (eds.), Formal syntax, 71-132. New York, NY: Academic Press.

Chomsky, Noam. 1993. A minimalist program for linguistic theory. In Ken Hale \& Jay Keyser (eds.), The view from Building 20. 1-52. Cambridge: MIT Press [Reprinted in Chomsky, N. 1995. The Minimalist Program, 167-217].

Chomsky, Noam. 1995. The Minimalist Program. Cambridge: MIT Press.

Chomsky, Noam. 2000. Minimalist inquiries: the framework. In Roger Martin, David Michaels \& Juan Uriagereka (eds.), Step by step: Essays in honor of Howard Lasnik, 89-155. Cambridge: MIT Press.

Chomsky, Noam. 2001. Derivation by phase. In Michael Kenstowicz (ed.), Ken Hale: A life in language, Cambridge, MA: MIT Press.

Chomsky, Noam. 2004. Beyond explanatory adequacy. In Adriana Belletti (ed.), Structure and beyond, 104-131. Oxford: Oxford University Press.

Cinque, Guglielmo. 2006. Restructuring and functional heads. Oxford: Oxford University Press.

Citko, Barbara. 2014. Phase theory. Cambridge: Cambridge University Press. DOI: https://doi.org/10.1017/ CB09781139644037

Clemens, Lauren \& Jessica Coon. 2018. Deriving verb-initial word order in Mayan. Language 94(2). 237 280. DOI: https://doi.org/10.1353/lan.2018.0017

Coon, Jessica. 2016. Mayan morphosyntax. Language and Linguistics Compass 10(10). 515-550. DOI: https://doi.org/10.1111/lnc3.12149 
Coon, Jessica, Nico Baier \& Theodore Levin. 2019. Mayan Agent Focus and the ergative extraction constraint: Facts and fictions revisited. Ms. McGill University.

Coon, Jessica, Pedro Mateo Pedro \& Omer Preminger. 2014. The role of Case in A-bar extraction asymmetries. Linguistic Variation 14(2). 179-242. DOI: https://doi.org/10.1075/lv.14.2.01coo

Davies, William D. \& Luis Enrique Sam-Colop. 1990. K'iche' and the structure of antipassive. Language 66(3). 522-549. DOI: https://doi.org/10.2307/414610

Dayley, Jon P. 1985. Tz'utujil grammar (University of California Publications in Linguistics 107). Berkeley, CA: University of California Press.

Deal, Amy Rose. 2016. Syntactic ergativity as case discrimination. In Aaron Kaplan, Abby Kaplan, Miranda K. McCarvel \& Edward J. Rubin (eds.), Proceedings of WCCFL 34, 141-150. Somerville, MA: Cascadilla Proceedings Project.

den Dikken, Marcel. 2009. Arguments for successive-cyclic movement through SpecCP: A critical review. Linguistic Variation Yearbook 9. 89-126. DOI: https://doi.org/10.1075/livy.9.03dik

den Dikken, Marcel. 2017. Overtly marked wh-paths. In Martin Everaert \& Henk C. Van Riemsdijk (eds.), The blackwell companion to syntax (second edition). Oxford: Wiley-Blackwell Publishing Ltd. DOI: https:// doi.org/10.1002/9781118358733.wbsyncom010

Douglas, Jamie, Rodrigo Ranero \& Michelle Sheehan. 2017. Two kinds of syntactic ergativity in Mayan. In Michael Yoshitaka Erlewine (ed.), Proceedings of GLOW in Asia XI, volume 2 (MIT Working Papers in Linguistics \#85), 41-56. Cambridge, MA: MIT Working Papers in Linguistics.

DuBois, John William. 1981. The Sacapultec language. Berkeley, CA: University of California dissertation.

Elbourne, Paul. 2001. E-type anaphora as NP-deletion. Natural Language Semantics 9(3). 241-288. DOI: https://doi.org/10.1023/A:1014290323028

England, Nora. 1989. Comparing Mam (Mayan) clause structures: Subordinate versus main clauses. International Journal of American Linguistics 55(3). 283-308. DOI: https://doi.org/10.1086/466121

England, Nora. 1991. Changes in basic word order in Mayan languages. International Journal of American Linguistics 57(4). 446-486. DOI: https://doi.org/10.1086/ijal.57.4.3519735

England, Nora. 1997. Topicalización, enfoque y énfasis. Cultura de Guatemala, año XVIII II(1). 273-288.

England, Nora. 2009. Keynote address. Talk given at the Conference on Endangered Languages and Cultures of Native America, University of Utah.

Erlewine, Michael Yoshitaka. 2016. Anti-locality and optimality in Kaqchikel Agent Focus. Natural Language and Linguistic Theory 34(2). 429-479. DOI: https://doi.org/10.1007/s11049-015-9310-z

Fox, Danny. 2002. Antecedent-Contained Deletion and the copy theory of movement. Linguistic Inquiry 33(1). 63-96. DOI: https://doi.org/10.1162/002438902317382189

García Ixmatá, Pablo (Ajpub’). 1997. Rukeemiik ja Tz’utujiil Chii’: Gramática Tz’utujiil. Guatemala: Editorial Cholsamaj.

García Matzar, Pedro (Lolmay) \& José Obispo (Pakal) Rodríguez Guaján. 1997. Rukemik ri Kaqchikel Chi’: Gramática Kaqchikel. Guatemala: Editorial Cholsamaj.

González, José Celestino Guarcax. 2016. Las cláusulas relativas en el kaqchikel de Sololá. Mexico, DF: CIESAS Master's thesis.

Grano, Thomas. 2017. Infinitives at the syntax-semantics interface: A diachronic perspective. In Lukasz Jedrzejowski \& Ulrike Demske (eds.), Restructuring at the syntaxsemantics interface. New York, NY: Mouton de Gruyter.

Heaton, Raina. 2017. A typology of antipassives with special reference to Mayan. Manoa, HI: University of Hawai'i dissertation.

Henderson, Robert. 2008. Observaciones sobre la sintaxis de la extracción de adjuntos en kaqchikel (maya). In B'alam Mateo Toledo (ed.), Memorias del congreso de idiomas indígenas de latinoamérica 3. Austin, TX.

Henderson, Robert \& Jessica Coon. 2017. Adverbs and variability in Kaqchikel Agent Focus: A reply to Erlewine (2016). Natural Language \& Linguistic Theory. DOI: https://doi.org/10.1007/s11049-0179370-3

Henry, Alison. 2012. Phase edges, quantifier float and the nature of (micro-) variation. Iberia 4(1). 23-39.

Hornstein, Norbert. 1999. Movement and Control. Linguistic Inquiry 30(1). 69-96. DOI: https://doi. org/10.1162/002438999553968

Kandybowicz, Jason. 2008. The grammar of repetition: Nupe grammar at the syntaxphonology interface. Amsterdam/Philadelphia: John Benjamins. DOI: https://doi.org/10.1075/la.136

Kayne, Richard S. 1994. The antisymmetry of syntax. Cambridge, MA: MIT Press.

Keine, Stefan. 2017. Agreement and vP phases. In Nicholas Lacara, Keir Moulton \& Anne-Michelle Tessier (eds.), A Schrift to Fest Kyle Johnson, 177-185. Amherst, MA: University of Massachusetts Amherst: Linguistics Open Access Publications 1.

Kiparsky, Paul. 1973. Abstractness, opacity, and global rules. In Osamu Fujimura (ed.), Three dimensions of linguistic theory, 57-86. Tokyo: Tokyo Institute for Advanced Studies of Language.

Koopman, Hilda. 2006. Agreement configurations: In defense of SPEC HEAD. In Cedric Boeckx (ed.), Agreement systems, 159-199. Amsterdam: John Benjamins. DOI: https://doi.org/10.1075/la.92.09koo 
Landau, Idan. 2006. Chain resolution in Hebrew V(P)-fronting. Syntax 9(1). 32-66. DOI: https://doi. org/10.1111/j.1467-9612.2006.00084.x

Landman, Meredith \& Rodrigo Ranero. 2018. Focus marking in Kuria. In Jason Kandybowicz, Travis Major, Harold Torrence \& Phillip T. Duncan (eds.), African linguistics on the prairie: Selected papers from the 45th Annual Conference on African Linguistics, 393-412. Berlin: Language Science Press.

Larsen, Thomas W. 1988. Manifestations of ergativity in Quiché grammar. Berkeley, CA: University of California dissertation.

Larsen, Thomas W. \& William M. Norman. 1979. Correlates of ergativity in Mayan grammar. In Frans Plank (ed.), Ergativity: Towards a theory of grammatical relations, 347-370. London: Academic Press.

Lasnik, Howard \& Mamoru Saito. 1992. Move alpha: Conditions on its application and output. Cambridge, MA: MIT Press.

Legate, Julie Anne. 2003. Some interface properties of the phase. Linguistic Inquiry 34(3). 506-516. DOI: https://doi.org/10.1162/ling.2003.34.3.506

López Ixcoy, Candelaria Dominga (Saqijix). 1997. Ri Ukemiik ri K’ichee' Chii': Gramática K’ichee'. Guatemala City: Cholsamaj.

Malchic Nicolás, Manuel, Romelia Mó Isém \& Augusto Tul Rax. 2000. Variación dialectal en Poqom. Guatemala: Editorial Cholsamaj.

Matsumoto, Mallory E. 2015. WI as a marker of pragmatic salience in the Kaqchikel Chronicles. Transactions of the Philological Society 114(1). 51-74. DOI: https://doi.org/10.1111/1467-968X.12063

McCloskey, James. 2002. Resumption, successive cyclicity, and the locality of operations. In Samuel David Epstein \& T. Daniel Seely (eds.), Derivation and explanation in the Minimalist Program, 184-226. Oxford: Blackwell Publishers. DOI: https://doi.org/10.1002/9780470755662.ch9

Mendes, Gesoel \& Rodrigo Ranero. 2017. Adjunct extraction: A view from Mayan. Paper presented at Berkeley Linguistics Society (BLS) 43.

Mó Isém, Romelia. 2007. Rikemiik li Tujaal Tziiij: Gramática Sakapulteka. Guatemala: Editorial Cholsamaj.

Norris, Mark. 2014. A theory of nominal concord. Santa Cruz, CA: University of California Doctoral dissertation.

Nunes, Jairo. 2004. Linearization of chains and sideward movement. Cambridge, MA: MIT Press. DOI: https://doi.org/10.7551/mitpress/4241.001.0001

Ordóñez, Francisco. 1995. The antipassive in Jacaltec: A last resort strategy. CatWPL 4(2). 329-343.

Par Sapón, María Beatriz \& Telma Angelina Can Pixabaj. 2000. Ujunamaxiik ri K'ichee' Ch'ab’al: Variación Dialectal en K'ichee'. Guatemala: Editorial Cholsamaj.

Patal Majzul, Filiberto, Pedro (Lolmay) García Matzar \& Carmelina Espantzay Serech. 2000. Rujunamaxik ri Kaqchikel Chi': Variación dialectal en Kaqchikel. Guatemala: Editorial Cholsamaj.

Perez Vail, José Reginaldo. 2014. La inversión y obviación en el mam de Cajolá. Mexico, DF: CIESAS Master's thesis.

Polinsky, Maria. 2016. Deconstructing ergativity: Two types of ergative languages and their features. Oxford: Oxford University Press. DOI: https://doi.org/10.1093/acprof:oso/9780190256586.001.0001

Postal, Paul. 1969. On so-called pronouns in English. In David Reibel \& Sanford Schane (eds.), Modern studies in english, 201-223. Englewood Cliffs, New Jersey: Prentice-Hall.

Pylkkänen, Liina. 2002. Introducing arguments. Cambridge, MA: MIT Doctoral dissertation.

Pylkkänen, Liina. 2008. Introducing arguments (Linguistic Inquiry Monographs 49). Cambridge, MA: MIT Press. DOI: https://doi.org/10.7551/mitpress/9780262162548.001.0001

Ranero, Rodrigo. 2020. Voice mismatches in Kaqchikel (Mayan) sluicing. To appear in Proceeding of WSCLA 24.

Roberts, Ian. 2010. Agreement and head movement: Clitics, incorporation, and defective goals (Linguistic Inquiry Monographs 59). Cambridge, MA: MIT Press. DOI: https://doi.org/10.7551/ mitpress/9780262014304.001.0001

Ross, John Robert. 1967. Constraints on variables in syntax. Cambridge, MA: MIT dissertation.

Sauerland, Uli. 2003. Intermediate adjunction with A-movement. Linguistic Inquiry. 308-314. DOI: https:// doi.org/10.1162/ling.2003.34.2.308

Shlonsky, Ur. 1992. Resumptive pronouns as a last resort. Linguistic Inquiry 23(3). 443-468.

Sichel, Ivy. 2014. Resumptive pronouns and competition. Linguistic Inquiry 44(4). 655-693. DOI: https:// doi.org/10.1162/LING_a_00169

Silberman, Pamela Ann. 1995. A survey of the use of wi in Kaqchikel: Spoken and written language norms. Austin, TX: University of Texas Master's thesis.

Stiebels, Barbara. 2006. Agent Focus in Mayan languages. Natural Language \& Linguistic Theory 24(2). 501-570. DOI: https://doi.org/10.1007/s11049-005-0539-9

Trinh, Tue. 2011. Edges and linearization - an investigation into the pronunciation of chains. Cambridge, MA: MIT dissertation. DOI: https://doi.org/10.1515/thli.2010.007

van Urk, Coppe. 2018. Pronoun copying in Dinka Bor and the Copy Theory of Movement. Natural Language and Linguistic Theory 36(3). 937-990. DOI: https://doi.org/10.1007/s11049-017-9384-x 

dissertation.

Wurmbrand, Susi. 1998. Infinitives. Cambridge, MA: MIT Doctoral dissertation.

Glossa: a journal of

general linguistics

Yasavul, Murat. 2017. Questions and answers in K'iche'. Columbus, OH: The Ohio State University

DOI: $10.5334 / \mathrm{gjgl} .1087$ dissertation.

TO CITE THIS ARTICLE:

Mendes, Gesoel and Rodrigo Ranero. 2021. Chain Reduction via Substitution: Evidence from Mayan. Glossa: a journal of general linguistics 6(1): 10. 1-31. DOI: https://doi. org/10.5334/gjgl.1087

Submitted:11 September 2019 Accepted: 26 August 2020 Published: 28 January 2021

COPYRIGHT:

(C) 2021 The Author(s). This is an open-access article distributed under the terms of the Creative Commons Attribution 4.0 International License (CC-BY 4.0), which permits unrestricted use, distribution, and reproduction in any medium, provided the original author and source are credited. See http://creativecommons.org/ licenses/by/4.0/.

Glossa: a journal of general linguistics is a peer-reviewed open access journal published by Ubiquity Press. 